NBER WORKING PAPER SERIES

\title{
THE IMPACT OF REGULATIONS ON THE SUPPLY AND QUALITY OF CARE IN CHILD CARE MARKETS
}

\author{
V. Joseph Hotz \\ Mo Xiao \\ Working Paper 11873 \\ http://www.nber.org/papers/w11873 \\ NATIONAL BUREAU OF ECONOMIC RESEARCH \\ 1050 Massachusetts Avenue \\ Cambridge, MA 02138 \\ December 2005
}

This paper reports the results of research and analysis undertaken while the authors were research affiliates at the Center for Economic Studies at the U.S. Census Bureau. It has undergone a Census Bureau review more limited in scope than that given to official Census Bureau publications. Research results and conclusions expressed are those of the authors and do not necessarily indicate concurrence by the Census Bureau. It has been screened to ensure that no confidential information is revealed. We thank the referees for excellent comments on previous drafts of this paper. We thank Juan Pantano for his excellent research support and Rebecca Acosta and Kevin McKinney at the California Census Research Data Center for their administrative support. We also thank Khalid Chaudhry, Mark Ginsberg, Siobhan Kelleher, and Pat Mucci at NAEYC for making the administrative accreditation records available to this study. Seminar participants at Carnegie Mellon, Duke, Princeton, Washington University-St. Louis, Penn State, UNC-Greensboro, Notre Dame, the Wharton School, UCLA, the 2005 International Industrial Organization Conference, the 2005 Census Research Data Center Conference, the 2008 ASSA Annual Meetings, the 2008 Econometric Society North American Summer Meetings, and the 2009 International Symposium on the Regulation of Occupations provided valuable comments.

(C) 2005 by V. Joseph Hotz and Mo Xiao. All rights reserved. Short sections of text, not to exceed two paragraphs, may be quoted without explicit permission provided that full credit, including $(\mathcal{C}$ notice, is given to the source. 
The Impact of Regulations on the Supply and Quality of Care in Child Care Markets

V. Joseph Hotz and Mo Xiao

NBER Working Paper No. 11873

December 2005, Revised August 2010

JEL No. L5,L8

\title{
ABSTRACT
}

We examine the impact of state child care regulations on the supply and quality of care in child care markets. We exploit panel data on both individual establishments and local markets to control for state, time, and, where possible, establishment-specific fixed effects to mitigate the potential bias due to policy endogeneity. We find that the imposition of regulations reduces the number of center-based child care establishments, especially in lower income markets. However, such regulations increase the quality of services provided, especially in higher income areas. Thus, there are winners and losers from the regulation of child care services.

\author{
V. Joseph Hotz \\ Department of Economics \\ Box 90097 \\ Duke University \\ Durham, NC 27708-0097 \\ and NBER \\ hotz@econ.duke.edu \\ Mo Xiao \\ 260 Heady Hall \\ Iowa State University \\ Ames, IA 50011-1070 \\ mxiao@email.arizona.edu
}


One of the most notable and consequential recent trends in the U.S. labor force has been the rise of women in the labor force, especially among those with young children. In 1975, $33.2 \%$ of mothers with children under age of 6 were employed; by 2005, this group's employment rate had increased by over 25 percentage points to $58.3 \% .{ }^{1}$ This increase, among other factors, fueled a substantial expansion of the market for child care services. In the spring of 2005, 7.2 million children under the age of 5 (36.9\%) were in some form of non-relative care, ${ }^{2}$ of which 4.6 million (23.3\%) were in some form of organized child care, i.e., a day care center, a nursery school/preschool or a Head Start program. Among employed mothers with a child under 5, 5.9 million of their children (52.1\%) were in non-relative child care, of which 3.6 million (31.9\%) were in an organized care facility. ${ }^{3}$

The increasing utilization of nonparental child care arrangements to care for preschool age children has led to a policy interest in insuring the quality and safety of these marketsupplied services. Child advocates and researchers argue that there is an under-provision of developmentally-enriching, high quality care services, ${ }^{4}$ either because parents are unable to evaluate and/or monitor the quality of services their children receive (Naci Mocan, 2007) or they fail to take account of the full social benefits of exposing their preschool children to developmentally-enriching child care. ${ }^{5}$ One response to this potential problem is for government

\footnotetext{
${ }^{1}$ U.S. Department of Labor, Bureau of Labor Statistics (2009), Women in the Labor Force: A Databook, Report 1018, September 2009.

${ }^{2}$ Non-relative child care consists of the following child care arrangements: 1) organized child care, i.e., child care centers, nursery schools and preschools and Head Start programs; 2) family day care homes, which is provided in the provider's home; and 3) other non-relative care, i.e., babysitters, nannies, etc., which is typically provided in the child's home. Children also may be cared for by relatives, including by grandparents, siblings and other relatives.

${ }^{3}$ U.S. Census Bureau. Who's Minding the Kids? Child Care Arrangements: Spring 2005, Tables 1A and 1B, http://www.census.gov/population/www/socdemo/child/ppl-2005.html.

${ }^{4}$ Studies by Marcy Whitebook, Carollee Howes, and Deborah Philips (1989) and the Cost, Quality and Outcomes Team (1995) estimate that only about $15 \%$ of all child care programs provide care that truly supports a child's physical, emotional and social and cognitive development.

${ }^{5}$ For example, parents may not take account of the externality that an ill-prepared child entering the first grade can
} 
to regulate the market for nonparental child care services with the intended consequence of improving their quality. In the U.S., such regulations are almost exclusively the domain of states. States do not regulate the quality of child care services directly. Rather, they impose standards for inputs to the production of child care services that are thought to improve the level of quality of these services. For example, most states require licensed child care providers to limit the number of children per staff in a facility or classroom, to hire staff that meet certain educational and training requirements and/or to require facilities and staff to meet certain safety standards.

At issue is whether such regulations necessarily improve the well-being, or welfare, of young children and their parents. While the regulation of such services may improve their quality, there are a number of reasons why they may have unintended consequences. First, because states regulate inputs, rather than quality itself, the mapping between the quality of services and the stringency of regulations is indirect at best. Regulations can induce providers to engage in input substitution that leads to no, or possibly negative, effects on the quality of child care services (David Blau, 2003 and 2007). For example, imposing a regulation that requires teachers in child care centers to have college degrees may not increase the quality of services if it induces child care centers to use less-skilled aides and fewer teachers. Second, to the extent that imposing regulations actually eliminates lower quality child care services, some parents and children - especially those who are poor - may be "priced out" of the market for such services or face inadequate supplies of such services. Finally, states only regulate part of the market for nonparental child care services and the stringency of these regulations can vary across types of child care providers. While most states regulate the providers of organized child care (e.g., child care centers), they often impose fewer and less stringent regulations on other non-relative forms

impose on the learning of other children (Edward Lazear, 2001). 
of care (e.g., family day care homes), and typically do not regulate care provided by relatives (e.g., grandparents) at all. Because compliance with regulations usually is costly and can result in higher prices, some parents may be induced to substitute away from regulated providers so their children may end up in lower quality care.

To determine the intended and unintended consequences of the child care regulation, we investigate the impact of imposing minimum standards on the inputs used in production of child care services on supply and quality of such services. For this purpose, we have assembled a unique panel dataset obtained by merging child care center data from the Census of Services Industries (1987, 1992, and 1997) with state regulation data and information on the accreditation of child care centers by the National Association of Education for Young Children (NAEYC). The resulting data set contains detailed information on establishments, including their legal form of organization, tax-exempt status, revenue, payroll, employment and accreditation, as well as the state-level child care regulations on various aspects of the provision of child care services. Furthermore, we have gathered state-level data on family day care homes for the corresponding Census years to examine the cross-effects of center regulations on this alternative form of child care.

Ours is not the first study seeking to estimate the causal effects of child care regulations on the supply side of the child care market. Studies by Tasmeen Chipty and Anne Witte (1997), Blau (2007) and others ${ }^{6}$ have examined the effects of state child care regulations on the input utilization, prices charged, wages paid and alternative measures of the quality of child care services. But, the data sources used in this study, and the econometric methods they allow us to employ, enable us to provide a more comprehensive and robust assessment of the impact of

\footnotetext{
${ }^{6}$ See William Gormley (1991), Anton Lowenberg and Thomas Tinnin (1992) and Chipty (1995).
} 
regulation on the supply side of the child care market compared to the existing literature in several ways. First, we are able to better address the identification of the causal effects of regulation on the choices made by child care providers. Previous empirical investigations are based on cross-sectional samples of child care centers and, as a result, must rely on the variation in regulations across states at a point in time for identification. While there is substantial variation in regulations across states, they are likely to be correlated with various factors that also directly affect the behavior of child care establishments, such as other state policies, labor market conditions, and the preferences of consumers. Failure to adequately control for these confounding factors in estimation can produce biased estimates of the causal effects of state regulations. We attempt to reduce, if not eliminate, such bias by exploiting panel data on child care centers and local child care markets to control for state, time, and establishment-specific fixed effects in the empirical models we estimate. Second, we not only exploit the across-state and over-time variation in the stringency of existing regulations, but also differences in whether states impose any regulations on certain dimensions of child care center operations. This allows us to distinguish between the marginal effect of changes in the stringency of a standard, evaluated at prevailing levels of stringency, and the average effect of imposing a standard relative to imposing none. As has been noted in the recent treatment effects literature, these two effects measure different things and can have different signs. ${ }^{7}$ Third, we investigate the indirect, cross effects of regulation of child care centers on family day care homes in order to assess the spillover and possible crowd-out effects of regulating only part of the market for child care services. Finally, we examine whether the impacts of the regulation of child care centers differ by the characteristics of local markets. In particular, we examine whether the imposition or

\footnotetext{
${ }^{7}$ See James J. Heckman and Edward Vytlacil (2005) and Richard Blundell and Monica Costa Das (2009) for more on the distinction between treatment effects in the presence of heterogeneity.
} 
stringency of regulations has different consequences for poorer versus wealthier markets in order to develop a better understanding of which consumers gain and which lose from regulating the provision of child care services.

We have three sets of findings. First, the imposition and greater stringency of regulations of child care centers reduces the number of these centers in local markets and thereby reduces the availability of such services to parents. Moreover, the magnitudes of these impacts on the number of centers for plausible changes in regulations are not trivial. We also find no evidence that the day care centers that remain in business respond to these regulations by hiring more workers to increase their size. Taken together, these findings indicate that the imposition and increased stringency of these regulations reduce the availability of services in the center-based sector of the child care industry. Moreover, this reduction of the availability of center-based child care is greater in poorer markets.

Second, we examine how regulating child care centers affects the home-based sector of the child care industry. While more stringent regulations of child care centers has no effect on the number of family day care homes in local markets, more stringent staff-to-child ratio requirements for child care centers do lead to higher revenues in family day care homes, with the larger increases in higher income markets. As we argue below, some or all of these higher revenues is the result of more children being cared for in these homes. Thus, some of the children who are crowded out of child care centers as a result of more stringent regulations end up in family day care homes, especially in higher income markets. Furthermore, this substitution to family day care homes is not accommodated by an increase in their staff, since the only staff in these homes are proprietors. ${ }^{8}$ What are the consequences of this substitution of types of child

\footnotetext{
${ }^{8}$ As we explain below, none of the family day care homes that we analyze have employees, so all of the labor is supplied by the proprietor.
} 
care for the well-being of parents and children? Based on the existing evidence (e.g., NICHD Early Child Care Research Network and Greg Duncan, 2003; Susanna Loeb, Margaret Bridges, Daphna Bassok, Bruce Fuller, and Russell Rumberger, 2007; Raquel Bernal and Michael Keane, 2010), it appears the crowding out of children from child care centers into day care homes, or other types of child care for that matter, is likely to hamper the cognitive development of preschool children and their readiness for primary school. Furthermore, this substitution results in an increase of the number of preschoolers per day care home which may adversely affect children's development, although no reliable evidence exists on the consequences of the latter.

Third, in contrast to the negative effects of more stringent regulations on the availability child care services in local markets, such regulations do increase the fraction of centers that are of sufficient quality to be accredited. We find conclusive evidence that the imposition and increasing stringency of state standards that regulate the labor intensiveness of child care center services significantly increase the rate of accreditation. It also appears that the average effect of imposing minimum educational requirements on child care center staff on accreditation rates is positive. Finally, the improvements in quality of child care services due to state regulations appear to accrue disproportionately to higher income markets, although these differences by income are not always precisely estimated.

The paper proceeds as follows. Section I frames our empirical analyses in the context of the theoretical literature and the particular features of the child care market. Section II discusses the data we use on child care establishments, state regulations, accreditation, and market definition. Section III describes our empirical methodology. Section IV presents our findings. Section V offers some concluding observations about our findings and their consistency with other evidence of the impacts of child of child care regulations for children in their parents. 


\section{Theoretical Considerations}

To help frame our empirical investigations and findings, we briefly review the existing theoretical literature on the effects of regulating the quality of products on the behavior of firms and indicate the key differences in the child care market from the settings considered in this literature.

The theoretical literature most relevant for our work is on the effects of minimum quality standards and/or licensing. Hayne Leland (1979), Carl Shapiro (1986), and Benjamin Klein and Keith Leffler (1981) focus on the effects of minimum quality standards or licensing requirements in the presence of informational asymmetries between buyers and sellers. Assuming a competitive environment, they argue that imposing binding minimum quality standards that increase the marginal cost of (higher quality) products can lead to low-quality firms exiting the market and deterring their future entry. At the same time, the imposition of minimum quality standards increases, all else equal, the average quality available to consumers, thereby increasing their willingness to pay a higher price for these goods and services. Which of these two effects the cost-of-quality effect and the quality-assurance effect - prevails depends on the availability of substitutes for the product, how price-sensitive consumers are with respect to the quality of products and the relative importance of the marginal to fixed costs of quality.

Consumer welfare, the distribution of quality in a market, as well as the profitability of firms, also is affected by the market structure. For example, Uri Ronnen (1991) and Claude Crampes and Abraham Hollander (1995) find that imposing more stringent minimum quality standards can induce quality (and possibly price) competition among sellers in markets that are less than perfectly competitive. That is, sellers may find it in their strategic interests to increase the quality of their products in response to the imposition of minimum quality standards, even though these standards are not binding on their pre-regulation quality levels. This is because 
high-quality sellers will want to produce even higher quality in order to differentiate themselves from firms selling lower-quality products to mitigate the degree of price competition with their regulated low-quality rivals. As a result, the quality of products of all firms in an industry, and not just those on whom the standards are binding, will increase, even if price competition between rivals may reduce the price of each firm's product. As a result, consumers are better off and their demand for all products will increase. More recently, Paolo Garella and Emmanuel Petrakis (2008) have shown that this strategic, quality-increasing and consumer welfareincreasing response to imposing minimum quality standards is sensitive to the degree of substitutability of products, the share of consumers in the market with limited information and the presence of variable costs of producing quality.

There are two important features of the child care market and its regulation that are not adequately captured in the existing theoretical literature. First, as noted above, states do not regulate the quality of child care services directly. Rather, they regulate the production of these services by imposing restrictions on the inputs used such as imposing minimum staff-to-child ratios for children in different age groups. Complications immediately arise from regulating inputs rather than quality directly as regulating inputs may distort care providers' incentives concerning input use and substitution. For example, providers may hire employees who are lower in quality of other dimension to satisfy education requirement. With such distortion, the success of these regulations in increasing and maintaining the quality of care provided in the child care market becomes in question. In the empirical analysis below, we explicitly investigate what happens to the quality of child care provided in local markets subject to more stringent child care regulations on inputs used in the production of such services.

Second, the existing theoretical literature does not adequately characterize the alternative 
options facing parents when assessing the impact of more stringent regulations on their choice of child care services. As noted in the Introduction, the child care market consists of two types of providers, child care centers and family day care homes that are subject to different regulations. Moreover, there are other options for the care of young children available to parents - such as the use of relatives or babysitters - that are not directly regulated at all. These "outside options" for child care services make the evaluation of welfare effects of imposing more stringent regulations on a subset of the providers in the child care market more complicated. For example, one might expect that more stringent regulations of child care centers would induce parents to move their children into the family day care sector. To the extent that there is capacity to absorb these children, evidence of reductions in available supply in the child care center sector would not necessarily imply any reduction of access by parents to market-based child care services. Moreover, the presence of these alternative forms of care is likely to influence the strategic response of firms in the regulated (or more highly regulated) sector in ways that are not captured by the above simple models. For example, more-regulated firms may want to switch to operate in the less regulated sector of the industry. A full exploration of how the imposition of regulations affects the behavior of firms and the well-being of consumers in the presence of segments of markets that are differentially regulated is beyond the scope of this paper. However, we do explore the extent to which regulations of child care centers affect the availability of child care in the less-regulated, loosely-structured sector of the market, family day care homes.

\section{The Data}

We combine several sources to create a unique panel dataset of child care centers, family day care homes, NAEYC accreditation, and state regulation. The main data we use on the child care industry is from the U.S. Census Bureau's Census of Service Industries. Every 5 years, the 
Census Bureau obtains data on all establishments in the service sector that filed federal income tax returns, regardless of whether they had tax liabilities. We are interested in those establishments listed as child care providers, preschools and Head-Start programs whose primary focus is the care of children under the age of five. Among these child care establishments, the Census Bureau distinguishes between those that are: (1) nonemployer establishments, which are owned by an individual and hire no employees; and (2) establishments that have an employee payroll with one or more employee in addition to the owner of the establishments. Child care centers fall into the second category of establishments, whereas family day care homes providers who care for preschool age children in their homes - fall into the first category. Accordingly, throughout the remainder of this paper, we shall refer to the establishments with payrolls as child care centers and those nonemployer establishments as family day care homes.

Under the Research Data Center program at the U.S. Bureau of the Census, we obtained access to establishment-level data for all child care establishments with an employee payroll for the Census of Service Industries conducted in 1987, 1992 and 1997. However, due to confidentiality concerns about nonemployer data in the Census of Services, we were not able to obtain the corresponding establishment-level for nonemployer establishments. ${ }^{9}$ Rather, as we describe below, we were only able to obtain data aggregated to the state level on this sector of the child care market. ${ }^{10}$ We do not have data on child care provided by relatives (e.g., grandparents) or non-relatives that care for children in the child's home (e.g., babysitters and

\footnotetext{
${ }^{9}$ In contrast to information obtained for establishments with an employee payroll, all of the information obtained on nonemployer establishments comes from tax returns collected and "owned" by the U.S. Internal Revenue Services (IRS). We were not granted access to the establishment-level data for the latter type of establishments.

${ }^{10}$ Thus, our data on family day care homes is for those proprietors who reported business income on the 1040 Schedule C of their individual/family returns or filed as a business entity with the Internal Revenue Service. It is possible that some of these homes did not comply with the federal tax code and, thus, may not be included in the data we use. However, we note that proprietors of family day care homes do have an incentive to file in order to claim allowable business expenses against either the personal or business incomes.
} 
nannies).

\section{A. Child Care Centers and Child Care Markets}

As noted, our primary analysis is of establishment-level data for all child care establishments with an employee payroll, i.e., child care centers, from the Census of Services in 1987, 1992 and 1997. For each of these establishments, we were given access in a secure site run by the Census Bureau to the following information: (a) Establishment identifiers, which we used to match establishments over time and determine the chain-status of an establishment. ${ }^{11}$ (b) Street address and business names for each establishment, which we used to organize our data into local geographic markets, link in data on various characteristics of these markets, and to link in a measure of the quality of the child care services described below from an external source. (c) Characteristics of these establishments and their operation, including the legal form of organization, tax-exempt status, operating receipts and revenues, operating expenses, number of employees, payroll, ownership, etc.

Child care markets are very localized markets. Few parents will travel more than fifteen miles to send their children to day care (Chipty, 1995; Sandra Hofferth, April Brayfield, Sharon Deich, and Pamela Holcomb, 1991). For most of the results presented below, we use zip codes as our measure of local markets. Based on the 2000 population Census, a typical zip code covers a radius of 3 to 4 miles, roughly consistent with the area that a child care center could cover. In order to assess the robustness of our findings based on our preferred zip-code market definition, we conducted all of our analyses using other definitions of local markets, including zip-code

\footnotetext{
${ }^{11}$ We define multiple establishments sharing the same IRS-generated establishment identification number (EIN) in the same Census year as affiliated with a chain. A chain has as few as 2 establishments and as many as around 1,000 establishments in the data.
} 
bundles and counties. $^{12}$

Finally, in order to characterize differences in the populations residing in our local child care markets, especially families with younger children, we used data from the 1990 and 2000 Censuses of Population to construct market-level measures of the demographic characteristics, including ethnic mix, median income of the local population; the percentage of population living in rural areas; the number of children under age 5; indicators of the typical household composition (e.g., the average number of people in a household and whether it is femaleheaded), labor market conditions (e.g., the percentage of females over 16 not working and the local unemployment rate), and indicators of commuting patterns (the percentage of the working population over 16 working at home and spending more than 40 minutes commuting). ${ }^{13}$ We include these variables as regressors in our establishment- and market-level analyses presented below.

After merging the data on child care centers across the three Censuses, we ended up with a panel dataset with approximately 150,000 establishment-year observations. We also organized our data into local markets under the alternative definitions noted above. Based on the zip-code definition, we had approximately 10,000 markets for each of the three years of the Censuses of Services. Using the data from these surveys, we constructed a number of different outcomes and characteristics of these centers at both the establishment and market levels. We provide summary statistics for the resulting establishment- and market-level data in Tables 1 through 5.

In Table 1 we summarize various characteristics of child care center establishment. There are several notable patterns. First, the number of child care establishments has dramatically

\footnotetext{
${ }^{12}$ We form zip-code bundles as the geographic areas encompassed by a zip code and all its neighboring zip codes within a 5-mile (or 10-mile) radius of the zip-code's population centroid.

${ }^{13}$ The 1990 Census of Population is merged into the 1987 and 1992 Census of Services, and the 2000 Census of Population is merged into the 1997 Census of Services.
} 
increased over the decade we analyze, rising from 40,628 in 1987 to 51,299 in 1992 to 61,882 in 1997, which is a rise of 26\% between 1987 and 1992 and 21\% from 1992 to 1997. Second, with respect to the type of local organization, child care centers in 1987 were most likely to be organized as a corporation (49.2\%), followed by an sole proprietorship (30.7\%), a partnership (4.0\%), and the remaining establishments having had some other legal structure, including being a government entity (16.1\%). Over the period, there was a slight increase in the percentage of child care centers that were incorporated, largely at the expenses of partnerships. In 1987, a little over one-third of centers were tax-exempt, not-for-profit entities, although the incidence of this status declines over time. About 18\% of centers were a part of a chain in 1987 and this rate grows slightly to $21.5 \%$ by 1997 . Third, despite the rise in centers organized as corporations, it is clear that these establishments are small businesses as they have a relatively small number of employees as well as modest payrolls and revenue. A typical child care center hires 8 to 10 employees depending on the year, paying around $\$ 10,000$ salary per employee and generating less than $\$ 25,000$ revenue per employee. At the same time, all three of these dimensions of centers increased over the period we examine.

In Tables 2 and 3, we provide summary statistics for child care markets, using zip-codes as the measure of local markets. In 1987, child care centers operated in roughly one third of all 30,000 U.S zip codes, and by 1997 in roughly half of these zip codes. On average, three to four child care establishments operate per zip code, about two of which have entered in the last five years, and one to two of which will exit in the next five years. For every 1000 children under 5 years of age, there are approximately 7 child care establishments in 1987, 8 in 1992 and 9 in 1992. Given the average numbers of employees an establishment hires (8 to 10) and the minimum staff-child ratio requirement (around 0.133 , or 7 or 8 children to every staff member) 
over the three Census years, it is straightforward to figure out that these establishments do have the capacity of accommodate a significant portion of children under 5. For example, in 1997 about 40 child care center employees in a typical zip code have the capacity of taking care of around 300 children, which account for about $25 \%$ of population under 5 . In Table 3 we provide summary statistics for the demographics of the zip codes in which child care establishments operate from the 1990 and 2000 Census of Population. They tend to be more heavily populated, wealthier, better-educated, and less-rural zip codes than the average U.S. zip code.

\section{B. Quality of Child Care Services: NAEYC Accreditation}

A key feature of our study is to examine the effects of regulation on the quality of child care services available to parents. There is a growing consensus among child developmental specialists that a good measure of whether a child care center provides high-quality services is whether it is accredited. ${ }^{14}$ The National Association of Education for Young Children (NAEYC) has administered a national accreditation system for almost two decades. Any early childhood program—child care center, preschool, kindergarten, or before- and/or after-school program— can voluntarily apply for NAEYC accreditation. The applying program must submit extensive information about its program and undergo a site-visit to validate the accuracy of this information. This includes assessments of the nature and extent of interactions among teachers and children, a center's curriculum, relationships between teachers and families, staff qualifications and professional development, the quality of a center’s administration, center staffing and the extent of staff turnover, a center's physical environment, whether a center meets various health and safety standards, and the quality of the nutrition and food services it provides.

\footnotetext{
14 The 1988 National Child Care Staffing Study (Whitebook, Howes, and Philips 1989) found that accredited child care centers provided higher-than-average-quality services to children and Mo Xiao (forthcoming) found that parents were willing to pay a premium for the accredited centers, especially newly opened centers that had not yet established a reputation about the quality of their services among parents.
} 
As a final step, this information is reviewed by a national commission of recognized experts in child care and early childhood education to determine whether a center meets NAEYC's criteria for a high quality child care program. If so, the commission accredits the center for a three-year period. In 1997, the last year in our data, around 6,500 programs were accredited. As we shall see below, this is a fairly small fraction of all child care centers, reflecting the fact that only very high quality programs are able to comply with the NAEYC's standards.

We obtained administrative accreditation records from the NAEYC, which contain information on the accreditation status of individual child care providers over the period 198797. These records included information on the provider's exact address (street address, city, county, state, zip) and information on their accreditation history (application date, initial accreditation date, expiration date, and accreditation status). We used this address information to determine the accreditation status of establishments in the Census of Services data in 1987, 1992 and 1997. We also used the NAEYC data to measure the fraction of child care center establishments that are accredited, or accreditation rates, by year for each of our local markets.

Accreditation rates at the establishment and market levels are recorded at Table 4. There is a substantial discrepancy in these rates, with accreditation rates based on establishment data substantially lower than those measured at the zip-code/market level. This discrepancy is a result of the lower rates of matching at the establishment level between the establishments in the Census of Services data and the NAEYC accreditation database. The latter was done using the addresses and names of establishments in the two data sets. In all three Census years, we only match approximately $60 \%$ of the NAEYC accredited establishments with Census establishments. If there is no match, we assume that the Census establishment was not accredited, which may be incorrect. The main reason for this low match rate, we suspect, is that many child care centers 
have changed their addresses and business names during our sample period. ${ }^{15}$ In contrast, the market-level accreditation rates were obtained by dividing the number of accredited establishments in the NAEYC data located in the geographical market, i.e., within a particular zip-code, by the number of child care center establishments from the Census data in that market. While also potentially subject to misclassification error, this latter set of rates only required matching on the geographical unit of the market, e.g., zip codes and, we suspect, are less subject to measurement/classification error. Focusing on the latter rates in Table 4, we find a sizeable increase in accreditation rates over time. While only $0.8 \%$ of child care establishments were NAEYC accredited in 1987, 3.8\% were accredited in 1992 and 9.4\% in 1997. Still, only a small proportion of establishments have received accreditation, which partially reflects the fact that the accreditation status serves as an indicator of high-end child care services.

\section{Family Day Care Homes}

Given the structure of the child care industry, it is important to assess whether regulation of child care centers leads to changes in the number of children cared for in family day care homes that comprise the less-organized sector of this industry. As noted earlier, we have more limited data for family day care homes - which the Census of Services classifies as nonemployer establishments - than we have for day care centers. In particular, we only have state-level data on these providers, including number of providers in a state in a given year and the total revenues these providers received for their services as claimed on their tax returns. We also do not have comparable measures of the quality of their services as we have for child care centers as NAEYC does not accredit family day care homes. Nonetheless, we are able to analyze the spillover effects of child care center regulations on several aspects of the operations in family day care

\footnotetext{
${ }^{15}$ The Censuses of Services records the addresses and the business names in 1987, 1992, and 1997 respectively, while the NAEYC only keeps the most recent addresses and business names.
} 
homes.

We present, in Table 5, descriptive statistics for family day care home establishments for the years 1987, 1992 and 1992. As one can see, there are a large number of these establishments. In 1997, there were on average 9,583 family day care homes per state or 488,734 in the nation as a whole, with family day care homes making up 89\% of all child care establishments in our data. We note that there appears to have been a large increase in the number of family day care homes between 1987 and 1992. While there may have been a dramatic growth of family day care homes between these two years, it is more likely that the 1987 number is the result of an undercount in these establishments. It turns out that 1987 was the first year in which nonemployer establishments were included in the Census of Services. Data from these establishments are obtained solely from federal tax returns and a substantial number of family day care homes were misclassified in terms of their industrial code in this initial year. ${ }^{16}$ We deal with this potential undercount in our empirical analyses of the effects of child care regulations by dropping 1987 nonemployer data for robustness check in our nonemployer regressions. Finally, we note that compared to child care centers, the average annual revenues of a family day care home is relatively low (\$9,382 in 1997), indicative of the fact that these establishments are truly small businesses. As the SIPP estimated that on average \$68 per week was paid per preschooler to family day care homes in 1997 (Smith, 2002), which amount to about \$3,000 per year, the average annual revenues of a family day care home suggests that a typical owner takes care of about 3 children.

\section{State Child Care Center Regulations}

In this section, we briefly describe the regulation of the child care industry and the data

\footnotetext{
${ }^{16}$ See Grace O’Neill and Martin O’Connell (2001) for more on the nonemployer establishment data for child care providers.
} 
we use to measure these regulations. Which aspects of a center's operation are regulated, and the stringency of those regulations, differs by types of child care provider. One set of regulations applies to center-based care provided in day care centers, preschool and/or nursery schools and Head Start programs. A different set applies to family day care homes, i.e., care provided by a provider, typically in their own home. Given that the primary focus of this paper is on the provision of center-based care, we limit our discussion to the regulation of this sector of the child care market.

In the analysis presented below, we focus on the effects of state regulations of the labor intensiveness (e.g., maximum child-to-staff ratios and group sizes by age group) and staff qualifications (e.g., minimum educational requirements and requiring criminal background checks for child care workers) of child care center services. ${ }^{17}$ Previous studies have found that these two aspects of the production of child care services appear to be associated with objective measures of child care quality, such as the cognitive, emotional and social development of young children. ${ }^{18}$ However, even within these categories of regulations, states tend to impose different standards for the care of children of different ages. Furthermore, as Blau (2003) points out and Currie and Hotz (2004) confirm, many of these regulations are highly correlated with one other. For example, states which impose stringent requirements on child-staff ratios also tend to restrict group sizes, i.e., the total number of children in a particular child care setting. This correlation makes it difficult to identify separate effects of individual regulations. Accordingly, we use two

\footnotetext{
${ }^{17}$ Other requirements include requiring use of a developmental curriculum, carrying liability insurance, and meeting certain health and safety standards such as immunization and fire-safety equipment. Some states even specify the frequency of government inspections on licensed child care centers.

${ }^{18}$ Ruopp, Travers, Glantz and Coelen (1979) and Mocan, Margaret Burchinal, John Morris, and Suzanne Helburn (1995) find evidence that more labor intensive and better qualified child care staff improve the development of young children. Also see Cheryl Hayes, John Palmer and Martha Zaslow (1990) and Blau and Currie (2006) for summaries of these and other studies. An important exception to these findings is Blau (2000). He finds, using the same data as in the Mocan, Burchinal, Morris, and Helburn (1995) study, that only educational qualifications have an effect on measures of children's development once one controls for center-specific fixed effects.
} 
alternative strategies to characterize state regulations. Under one strategy, we make use of sets of representative standards for labor intensity and staff qualifications, such as staff-child ratio requirements for infants and the education requirement for directors since most states regulate these dimensions and they differ across states. ${ }^{19}$ This strategy is used by Chipty and Witte (1997), Blau (2007) and Currie and Hotz (2004). Following Blau (2003), we also construct summary indices of the stringency of state standards for labor intensiveness and staff educational qualifications. In particular, for staff-child ratio requirements, we average the requirements for the six age groupings and, for staff qualifications, we use the average of the number of years of schooling required for center directors and teachers.

Table 6 presents summary statistics for the minimum staff-to-child ratios for child care centers and educational requirements for center directors and teachers in 1987, 1992, and 1997. ${ }^{20}$ On the surface, there are no discernable trends in the various measures of regulation amongst those states that had regulations. However, one does see an increase in the number of states that began to regulate certain aspects of the production of child care services over this period. For example, between 1987 and 1997 five states started regulating staff-child ratios for infants and 4 states changed its regulatory stringency and ten states went from no regulation on directors' education levels to having a regulation. More generally, as shown in the last column of Table 6, a sizeable number of states changed their individual regulations over this period. This variation i.e., where states changed particular regulations over our sample period - will turn out to be essential for our ability to identify the causal effects of these regulations on the availability and quality of child care services. We also note that there is considerable variation in the stringency

\footnotetext{
${ }^{19}$ The staff-child ratio requirements for toddlers and preschoolers have comparable variation in data, but labor intensiveness matter the most for infants.

${ }^{20}$ The information on state child care regulations was gathered by Hotz, in collaboration with Rebecca Kilburn of Rand for the period 1983-1997. These data are available upon request.
} 
of regulations across states. Some states (e.g. Maryland, Kansas, and California) require one staff member to take care of no more than 3 or 4 toddlers, while other states (e.g. South Carolina, Idaho) allow one staff member to take care of as many as 8 to 12 toddlers. As for the education requirements, states range from imposing no educational requirements on any child care center employees (e.g., Florida, Idaho) to requiring that directors have high-school diplomas (e.g., Connecticut, Michigan), to requiring that child care center directors and teachers have some college education (e.g. South Dakota, New Jersey).

\section{Econometric Methods}

In this section, we briefly outline our estimation strategy and describe the alternative measures of the effects of regulation.

As we noted in the introduction, there is a potential for bias in the estimation of the causal effects of regulation stringency on the child care market. The most challenging source of such bias is "policy endogeneity" (Timothy Besley and Anne Case, 2000), i.e., the possibility that state policies are influenced by (or correlated with) unobserved state-level factors or conditions that influence the behavioral outcomes under investigation. For example, suppose some states may have a high proportion of parents who prefer to provide their children with high quality child care - and are willing to pay for it - while the parents in other states do not. Furthermore, suppose that parents vote their preferences and either support or oppose the imposition and stringency of regulations as a way to promote higher quality child care. Then failure to control for the potentially unobserved differences in the distribution of tastes across states - as well as other differences across states and over time - will result in biased estimates of the effects of policy on the outcomes of interest.

To mitigate the influence of this type of policy endogeneity, we exploit two features of 
our data. First, we control for as rich a set of observable establishment- and market-level characteristics that might account for this source of bias in the regression analyses presented below. Second, we exploit our panel data on establishments and local markets to control for state, time, and, where possible, establishment fixed effects in these regression models. Including establishment fixed effects in these models not only controls for time-invariant state-specific sources of unobserved heterogeneity - none of the child care establishments in our data are observed to relocate across state lines - but also controls for time-invariant establishment-level factors that could cause bias in our estimates of the effects of regulations. More precisely, for market-level analyses we can estimate regressions of the following form:

$$
Y_{m s t}=\alpha_{0}+\alpha_{1} R E G_{s t}+\alpha_{2} N o R E G_{s t}+\alpha_{5} X_{m s t}+\delta_{t}+\gamma_{s}+\varepsilon_{m s t},
$$

where $Y_{m s t}$ are outcomes of interest for market $m$ in state $s$ in year $t, R E G_{s t}$ is a vector of the child care regulations in that state as of year $t, N o R E G_{s t}$ is a vector of dummy variables that equal 1 if the state did not mandate a particular regulation in year $t$ and equal to 0 otherwise, $X_{m s t}$ is a vector of market-level population characteristics and economic conditions, $\delta_{t}$, and $\gamma_{s}$, are, respectively, year and state fixed effects, and $\alpha_{1}$ is the vector of the impacts of state child care regulations on $Y_{m s t}$. And, for establishment-level analyses, we can estimate the following regression models:

$$
Y_{j m s t}=\beta_{0}+\beta_{1} R E G_{s t}+\beta_{2} N o R E G_{s t}+\beta_{5} X_{m s t}+\beta_{6} Z_{j m s t}+\omega_{t}+\lambda_{s}+\kappa_{j}+v_{j m s t},
$$

where $Y_{j m s t}$ are outcomes for establishment (child care center) $j$ located at local market $m$ within state $s$ in year $t, Z_{j m s t}$ denotes a vector of establishment characteristics, $\omega_{t}, \lambda_{s}$ and $\kappa_{j}$ are, respectively, time, state and establishment fixed effects and $\beta_{1}$ is the vector of the impacts of 
state child care regulations on $Y_{j m s t}{ }^{21}$ In order to examine how the effects of regulations differ across the population of consumers (parents), we also estimate the following variants of (1) and (2):

$$
\begin{aligned}
Y_{m s t}= & \alpha_{0}^{*}+\alpha_{1}^{*} R E G_{s t}+\alpha_{2}^{*} N o R E G_{s t}+\alpha_{3}^{*} R E G_{s t} \cdot C_{m s t}+\alpha_{4}^{*} N o R E G_{s t} \cdot C_{m s t} \\
& +\alpha_{5}^{*} X_{m s t}+\delta_{t}^{*}+\gamma_{s}^{*}+\varepsilon_{m s t}^{*}, \\
Y_{j m s t}= & \beta_{0}^{*}+\beta_{1}^{*} R E G_{s t}+\beta_{2}^{*} N o R E G_{s t}+\beta_{3}^{*} R E G_{s t} \cdot C_{m s t}+\beta_{4}^{*} N o R E G_{s t} \cdot C_{m s t} \\
& +\beta_{5}^{*} X_{m s t}+\beta_{6}^{*} Z_{j m s t}+\omega_{t}^{*}+\lambda_{s}^{*}+\kappa_{j}^{*}+v_{j m s t}^{*},
\end{aligned}
$$

where $C_{m s t}$ denotes characteristics of the populations of local markets and we use median household income as such a characteristic in this study.

The inclusion of state and establishment fixed effects implies that our effects of regulations are identified holding constant any time-invariant differences across markets in (1) and any time-invariant differences across establishments in (2). ${ }^{22}$ The inclusion of year fixed effects implies that we also hold constant any shocks which hit all the states in the same year. Our data allow us to support a richer set of strategies to mitigate policy endogeneity bias than any previous attempts to estimate the effects of regulations on the availability or quality of child care services. $^{23}$

The specifications in the above regression models allow us to estimate two alternative and distinct effects of regulations on $Y_{m s t}$ and $Y_{\text {jmst. }}$ The coefficients $\alpha_{1}$ and $\beta_{1}$ in (1) and (2), respectively, measure the marginal effect of a change in the stringency of an existing standard,

\footnotetext{
${ }^{21}$ Controlling for firm, rather than establishment fixed effects - multiple establishments can belong to the same firm - produced results that were similar to those reported below.

${ }^{22}$ The extent to which there are other, unobserved market-level factors that are time-varying and correlated with our regulation variables, our results still may be biased.

${ }^{23}$ Both Chipty and Witte (1997) and Blau (2007) use cross-sectional data to identify the effects of regulations on the supply and quality of child care services. For example, Blau (2007) uses a detailed cross-sectional sample of child care centers surveyed in four states and uses within state variation in differences in regulations by age groups of children and by types of center staff to estimate causal effects of these regulations.
} 
$R E G$, given that this dimension of child care is regulated. ${ }^{24}$ This causal effect considered in previous studies of child care services. But, as suggested by the theoretical work on the effects of regulations discussed in Section I, one is often interested in the effect of imposing some standard relative to no standard at all. This latter effect corresponds to average treatment effects considered in the evaluation literature. In particular, let $Y_{1}$ denote the potential outcome when a state regulates a particular dimension of child care centers and $Y_{0}$ denote the potential outcome when it does not. Then, the average effect of regulation is defined to be

$$
E\left(Y_{1}-Y_{0} \mid R E G=\tilde{R}\right)= \begin{cases}\theta_{1} \tilde{R}-\theta_{2} & \text { in (1) and (2) } \\ \theta_{1}^{*} \tilde{R}+\theta_{3}^{*} \tilde{R} \cdot \tilde{C}-\theta_{2}^{*}-\theta_{4}^{*} \tilde{C} & \text { in (1') in (2') }\end{cases}
$$

where $\theta_{i}=\alpha_{i}$ in (1) and $\beta_{i}$ in (2) and $\theta_{i}^{*}=\alpha_{i}^{*}$ in $\left(1^{\prime}\right)$ and $\beta_{i}^{*}$ in (2'). Below, we present estimates of the average effect of a regulation at its sample mean, i.e., $\tilde{R}=\bar{R}$.

It is important to note that the marginal effect and average effect of regulation characterize two different effects of regulation and, in general, they need not be of the same sign. The regression specifications above allow for this possibility. For example, it follows from (3) that the average effect of imposing any regulation, evaluated at certain level of regulation, $\tilde{R}$, is positive, even though the marginal effect of a change in that level is negative.

Finally, we estimate the variance matrix taking into account unobserved heterogeneity influencing seller behavior at the state-year level in all sets of regressions. Specifically, we allow the error terms to cluster by state-year group, that is, we allow each state-year group to have a different and unrestricted covariance structure but assume that errors are uncorrelated across

\footnotetext{
${ }^{24}$ The corresponding measures of marginal effects for alternative values of $C_{m s t}=\tilde{C}$ are given by $\alpha_{1}^{*}+\alpha_{3}^{*} \tilde{C}_{m s t}$ and $\beta_{1}^{*}+\beta_{3}^{*} \tilde{C}$, respectively.
} 
groups (Brent Moulton, 1986). ${ }^{25}$

\section{Results}

Tables 7 through 12 present results on the effects of state child care regulations on the supply and quality of child care services. To keep the size of these tables manageable, we only report the coefficients on our regulation variables and their interactions with the median household income in the local markets. ${ }^{26}$ For every table, we include two panels: the upper panel (Panel A) presents estimates of the effects of specific regulations, i.e., those for the minimum staff-child ratio requirement for infants in day care centers and educational requirements for center directors. The bottom panel (Panel B) presents estimated effects of the stringency indices on minimum staff-child ratio and educational requirements that we described in Section II.

We begin by making some general observations about our empirical findings. First, we consistently find that the estimated effects of regulations (marginal effects and average treatment effects) that control for time, state and/or establishment fixed effects are markedly different from those that do not. For example, the estimated effects results often switch signs - including from negative and significant to positive and significant - when we control for fixed effects. Furthermore, unlike in Blau (2007), we do not find that controlling for fixed effects systematically render the estimated effects of regulations to be statistically insignificant. Rather, for many outcomes, regulations do significantly affect firm behavior, even after we control for various sets of these fixed effects. Second, the signs and statistical significance of the effects of regulations on firm and market-level outcomes are not very sensitive to whether we use direct

\footnotetext{
${ }^{25}$ If we cluster error terms by state instead of state-year pair, we lose significance in a few cases but our inferences about the effects of regulations remain largely intact.

${ }^{26}$ In all of our regressions, we control for the variables listed in the top part of Table 1 and in Table 3 . Versions of Tables 7 to 12 with a complete set of coefficient estimates and their robust standard errors are available at www.econ.duke.edu/ vjh3/working_papers/Hotz-Xiao-Tables.pdf.
} 
measures of regulations or the stringency indices we constructed. Nor are our results on the effects of minimum staff-child ratios or staff educational requirements sensitive to whether we hold constant measures of regulations on other dimensions of the production of child care services or whether we control for indicators of whether a state actually imposed any regulatory restriction. Finally, the signs and statistical significance of the effects of regulations on the outcomes we exam are robust to the particular way we define local markets, i.e., whether they are defined local markets as zip codes, zip code bundles, or counties. To conserve on space, we do not report on all of the robustness checks we performed. Detailed results for these analyses are available upon request.

\section{A. Effects of Regulations on the Number of Child Care Centers in Local Markets}

As we noted in Section I, one cannot sign the effects of the imposition of regulatory standards or of increasing their stringency on the production of child care services. They depend on the balance between the increased costs centers face of complying with regulations and the increased willingness of consumers to pay higher prices for care because of their increased assurance of the quality of services. Moreover, the fact that inputs, rather than quality, are regulated implies that the mapping between the quality of services and the stringency of regulations is not as direct as suggested by the theoretical literature on minimum quality standards. In this section, we examine estimates of the net effect of these forces on the supply of child care services as measured by the number of establishments per local market.

Table 7 presents results on the effects of state child care regulations on the number of child care centers in a local market, using zip codes to define these markets. The regressions both without and with state and time fixed effects (column 4) show that the average effect of imposing minimum staff-child ratio requirements, where the regulation is evaluated at its sample mean 
(estimates in "Ave. Effect of Regulation" rows) and the marginal effect of increasing the stringency of this standard significantly reduce the number of establishments operating in a local market, although the average effect of the minimum staff-child ratio regulation is not statistically significant. To get a sense of how sizeable this effect is, consider the marginal effect of increasing the minimum staff-child ratio from its mean of 0.226 (see Table 6) to 0.292 , which amounts to reducing the average maximum number of infants per staff member in a child care center by 1 infant. ${ }^{27}$ Based on the estimates from Panel A, column 4 of Table 7, such an increase in the stringency of the staff-child ratio for infants would reduce the number of child care centers in the average market by between $9.2 \%$ and $10.8 \%$ depending on the year analyzed. Meanwhile, the marginal effect of increasing the average required number of years of education of center directors by 1 would reduce the number of child care centers in the average market by between $3.2 \%$ and $3.8 \%$ depending on the year analyzed. While not huge, the marginal effects are not trivial reductions in the availability of child care centers.

The estimated effects of child care regulations on the availability of child care centers in Table 7 are not uniform across different markets. In column 5 of Table 7, we provide estimates of the interaction of the various regulations with the median household income in the local markets. As one can see, the interactions of the staff-child ratios in both Panels A and B are statistically significant. Furthermore, the positive coefficient on the interactions of these ratios with the median income of households in the local markets are positive, indicating that the effect of increases in the stringency of minimum staff-child ratios is larger in wealthier markets. At the

\footnotetext{
${ }^{27}$ The average of the minimum staff-child ratio for infants is 0.226 (Table 6), which corresponds to a maximum child-staff ratio of 4.425 . Thus, reducing the number of infants per staff member by one implies that the associated minimum staff-child ratio would be $0.292(=1 /[4.425-1])$. Thus, the minimum staff-child ratio would increase by $0.066(=0.292-0.226)$. Then the estimated reduction in the number of centers in an average local market would be $-0.371(=-5.617 \times 0.066)$,) corresponding to $9.2 \%(=0.371 / 4.023)$ of average number of child care centers in a zip code in 1997 , and $10.8 \%(=0.371 / 3.440)$ in 1987 . The following calculations all follow this procedure.
} 
same time, the interactions of median income with minimum educational requirements in either Panel A or B are not statistically significant and tend to be small, indicating that there is little evidence that the effects of this latter set of regulations vary by the income of households in local markets.

To provide a better sense of how the impacts of the marginal and average effects of regulations vary by the median household income of local markets, we present, in column 1 of Table 8, the implied estimates of both the marginal and average effect of regulations for local markets with higher median income markets (evaluated at 2 standard deviations above the sample median) and for lower income markets (evaluated at two standard deviations below the sample median). With respect to these effects, the negative impacts of the imposition of minimum staff-child ratios (“Ave. Eff.” column) and increasing their stringency (“Marg. Eff.” column) are concentrated in poorer markets. In fact, based on our points of evaluation, the imposition of minimum staff-ratios or increasing their stringency actually increase the number of child care centers (establishments) in higher income markets. One possible explanation for this difference is that wealthier households may respond to tighter standards by increasing their demand for child care center services consistent with the dominance of the quality-assurance effect suggested by some of the theoretical models discussed in Section I. In contrast, markets with poorer households may be more affected by the increase costs that result from such regulations, i.e., the cost-of-quality effects dominate any quality-assurance effects of the imposition or tightening of minimum staff-child ratios in this sector. We will provide more evidence below on the plausibility of this explanation when we look at the differential effects of regulation by household income on our measure of quality (accreditation) and on the costs (labor costs) of center-based care. 
As we noted above, we estimated a number of alternative specifications of our baseline model to determine the robustness of our findings concerning the marginal and average effects of regulations on all of our outcomes. In Table 9 we present a few of these robustness checks for the number of establishments per market. Comparing the estimates of the marginal and average effects of regulation in Table 9 with those in Table 7, we see that across changes in our measures of regulations, whether or not we control for other state regulations and using alternative definitions of local markets, we consistently find negative and statistically significant effects of more stringent staff-child ratios on the number of child care centers per market. With respect to imposing minimum educational requirements for child care center staff or increasing their stringency, while the estimated effects are less consistently statistically significant, the estimated effects are almost always negative in sign.

Overall, we find consistent evidence that the imposition of and tightening of minimum staff-child ratios lead to a reduction in the availability of child care centers in local markets. Our findings with respect to the effects of minimum educational requirements on the supply of centers to local markets are somewhat less consistent in that statistical significance varies by which type of effect one considers and somewhat by household income. Nonetheless, we do find rather consistent evidence that, on average, imposing minimum requirements on the educational qualifications of center staff reduces the availability of centers in local markets. ${ }^{28}$

\section{B. Effects of Regulations on the Size of Centers}

The previous section established that the imposition and increased stringency of child care regulations reduce the number of child care centers available in local markets. However,

\footnotetext{
${ }^{28}$ We also examined the effects of state child care regulations on the market rates of entry and exit to determine whether the negative effects of such regulations on the number of establishments per market is the result of regulations forestalling entry or increasing the rate at which incumbent centers leave the market. We find evidence that imposing and increasing the stringency of these regulations do both.
} 
these findings do not imply that the capacity of center services in these markets is necessarily reduced, since the remaining providers could increase the labor they use, and thus the size of their operations, in response to changing regulations and possibly completely offset the loss of centers. More generally as noted by Blau (2007), child care centers may adjust their labor inputs in response to changes in these regulations, regardless of whether such responses increase or decrease the production of child care services. Accordingly, we directly examine the effects of the stringency of state child regulations on the number of employees per child care establishment using establishment-level data. The results of this analysis are presented in Table 10. While we do find significant effects of regulations when we do not control for establishment fixed effects (columns 1 and 2), none of these effects are statistically insignificant once these fixed effects are

included in the regressions (columns 3 and 4). The latter findings suggest that the centers that remain in business do not fully comply with states' minimum staff-child ratios or that these centers end up reducing the number of children they cared for. Our data do not allow us to sort out these alternatives, since we do not have information on the number of children enrolled in a child care center. But, taken together with our evidence that the number of establishments decline as a result of the imposition of and increased stringency of state regulations, these findings do point to the conclusion that such changes in regulations reduce the supply of centerbased child care services in local markets.

\section{Effects of Center Regulations on Family Day Care Homes}

As we noted in Section I, the imposition and increased stringency of regulation of child care centers may increase the demand for non-center-based child care services, including those provided in family day care homes, to the extent that such regulations either increase the price of center-based services and/or otherwise reduce their availability. We now examine the evidence 
on whether this "crowding in" to family day care homes occurs and assess its likely consequences for the well-being of children and their parents. Recall that we only have statelevel data on family day care homes. Thus, our analysis of the cross-sector effects of child care center regulations is more restricted relative to that for child care centers. Nonetheless, we think they are informative.

In Table 11 and column 2 of Table 8, we present estimates of the marginal and average effects of state child care center regulations ${ }^{29}$ on the number of family day care homes (nonemployer establishments) per 1000 children under age 5 in a state to determine how child care center regulations affect the supply of family day care homes. We also present estimates of effects of regulations on the average annual revenues per family day care home. In addition to being of direct interest, we argue below that any cross-sector effects of child care center regulations on the revenues of family day care homes is likely to track changes in the number of children (or child hours) in these homes. Finally, the data used to generate the estimates in Table 11 include the 1987 data, the year for which there appears to be an undercount of family day care homes. However, our findings and inferences about the effects of regulations on either of the family day care home outcomes are little affected by excluding the 1987 data.

With respect to the effects of state child care center regulations on the number of family day care homes relative to the number of preschool age children (columns 1 and 2 in Table 11), there is little evidence of any cross-regulation effects as almost all of the estimated coefficients are statistically insignificant. Moreover, the average effects of imposing minimum staff-child ratios and educational attainment on child care centers employees are negative in all but one case, implying, if anything, that the imposition of child care center regulations reduced the

\footnotetext{
${ }^{29}$ We also estimated versions of the regression models that also included measures of states' regulations that apply to family day care homes. Controlling for these additional variables has little impact on the estimates and significance of the effects of state child care center regulations.
} 
number of family day care homes in states. ${ }^{30}$ However, we find positive and statistically significant estimate of average and marginal effects of regulating center-based staff-child ratios on the average annual revenue per family day care homes (Table 11, columns 3 and 4). Furthermore, while the marginal effect of increasing the stringency of the educational requirements of center directors is negative, the average effect of this regulation is positive, consistent with those for center-based minimum staff-child ratios. Finally, we find that the average effect of regulating the center-based staff-child ratios varies by a market's median household income (Table 11, column 4), with such regulations resulting in higher revenues per establishment in higher income markets relative to poorer ones. In fact, our estimates imply that revenues actually fall in very poor markets as a result of tighter regulation of center-based care (Table 9, column 2).

What do these results for the cross-effects of regulations imply for the well-being of children and their parents? Although the number of family day care homes does not increase in response to tighter regulation of the center-based sector, it does appear that there is an increase the number of children per home. The latter is an implication of the cross-regulation effects on family day care home revenues. While more stringent center-based regulations may result in an increase in the prices charged by family day care homes, some or all of the estimated increase in the revenues in these homes is the result of an increase in the number of children that they serve and/or children-hours they provide. ${ }^{31}$ In principle, this accommodation of children by family day care homes that are crowded out of center-based care due to the regulation-induced reduction of

\footnotetext{
${ }^{30}$ Given this lack of statistical significance, we do not present how the estimated regulation effects differ by household income in Table 8.

${ }^{31}$ In fact, one would expect the increase in the quantity of care provided to be greater than an increase in its price, since the relatively low costs of establishing a family day care home are likely to keep this sector of the child care market relatively competitive.
} 
capacity in the latter sector should help meet the child care demands of parents, especially employed mothers.

At the same time, there are several reasons to conclude that crowding children out of center-based care and into family day care homes may have adverse consequences for their development. First, a number of recent studies (NICHD Early Child Care Research Network and Duncan, 2003; Loeb, Bridges, Bassok, Fuller and Rumberger, 2007; Bernal and Keane, 2010) ${ }^{32}$ have found that children in center-based care, especially between the ages of 3 and 4, have higher levels of cognitive and language skill development and school readiness by the age of 5 than do children who spend an equivalent amount of time in family day care homes of comparable quality. In fact, these studies consistently find positive differential effects of child care centers relative to other child care arrangements, including that provided by babysitters, nannies and relatives. Furthermore, several of these studies find that the developmental benefits of center-based care are typically greater for children in poor and/or minority families. Second, as noted above, our estimated cross-effects of regulation on family day care home revenues imply that additional children cared for in these homes are cared for by the same number of staff, which also could adversely affect the development and school readiness of young children. Unfortunately, there does not appear to be any evidence on the effects of differences in the number of children per provider within family day care homes on measured outcomes of children.

\footnotetext{
${ }^{32}$ Blau and Currie (2006) and Duncan and Christina Gibson-Davis (2006) argue that many, if not most, studies of the effects of alternative types of child care and their quality on children's cognitive development, school readiness and related outcomes are not based on random assignment of these arrangements, and, as such are potentially subject to selection bias. While there are no studies, to our knowledge, that have used random assignment to identify the differential effects of alternative child chare arrangements on children's outcomes, the studies cited above do attempt to use one or more non-experimental methods to try to alleviate this source of bias.
} 


\section{Effects of Regulations on Quality of Child Care Centers}

We next examine whether child care regulations achieve their goal of increasing the quality of child care services. Existing theories of regulation suggest that whether regulation promotes the quality of child care services depends on whether the quality-assurance effects of such regulations outweigh the greater costs of producing higher quality services. Furthermore, as noted by Blau (2003), the fact that child care regulations affect the inputs used in the production of quality, and not quality itself, implies that imposing or tightening regulations could induce the substitution of other inputs and have little or no effect on quality. Finally, the models of Ronnen (1991) and others suggest that imposing or tightening minimum standards on quality can induce quality competition in markets that are less than perfectly competitive. In the analysis that follows, we are unable to explicitly test the validity of these alternative avenues through which child care regulations affect the quality of center-based care. Rather, we focus on the average and marginal effects of regulation on the quality of center-based care in local markets.

We present, in Table 12, estimates of the average and marginal effects of child care regulations on the percentage of child care centers in local markets that are accredited by NAEYC, i.e., market accreditation rates. As we noted in Section II, it appears that the rates of accreditation based on establishment-level data are understated due to the difficulties of matching child care centers in the NAEYC accreditation database with establishments in the Census of Services data. We argued that market-based accreditation rates were less susceptible to this understatement, given that such matches only required matching on zip codes and not full addresses. While only reported in the on-line appendix, we also estimated the effects of regulation on the probability of child care centers accredited using establishment-level data. In most cases, the signs and statistical significance of the average and marginal effects were the 
same as those presented in Table $12 .^{33}$

We find that the imposition of and increased stringency of minimum staff-child ratio requirements significantly increase the rates of accreditation in local markets. We also find that the marginal effects for both of our measures of minimum educational requirements for child care center staff in Panels A and B are negative, although the marginal effect of our average measure of these requirements (Panel B) are not statistically significant. Furthermore, our estimates of the average effects of these regulations are either positive or negative but are not statistically significant. Thus, our evidence indicates that the imposition of either type of regulation increases the quality of center-based care available in local markets. This is consistent with the quality-assurance effect dominating the cost-of-quality effect among typical consumers and with the regulation of these inputs actually improving the quality of child care. It is also consistent with Ronnen's prediction that imposing minimum quality standards will not only reduce the provision of low-quality services, but also will generate strategic increases in the quality provided by already high-quality centers. Recall that attaining NAEYC accreditation requires a center to meet a set of minimum standards for its operation that are well above the minimum standards imposed by any state.

Finally, based on the estimates of coefficients on the interactions of the regulations with the median household income in Table 12, we find that any increases in the quality of centerbased care that result from the imposition of these regulations only accrue to high income markets (Table 8, column 3), although the interactions with income are only statistically significant for the average minimum educational requirements measure in Panel B of Table 12. In fact, the effect of imposing these standards on quality is consistently negative in very poor

\footnotetext{
${ }^{33}$ The only notable differences between the latter results and those reported in Table 12 are for the coefficients on the minimum educational requirements variables, where there were differences in levels of statistical significance although virtually no differences in the signs and magnitudes of the estimates themselves.
} 
local markets. The latter findings suggest that any quality-assurance effects of imposing regulations are swamped by the effects of the higher costs of quality among the poor.

\section{Conclusions}

Imposing regulations on quality of inputs or directly on quality has an extensive history in a number of sectors of the economy, ${ }^{34}$ including the market for child care services. However, the imposition of minimum quality standards on inputs used in production of child care services is only one of many regulatory responses to such market failure. ${ }^{35}$ In the face of these alternative responses, policy makers need to be fully informed of the consequences - intended or unintended - of such regulations.

Based on our findings, these consequences for the well-being of children and their parents appear to be both positive and negative. On the negative side, we find that the imposition of input regulations in the center-based sector of the child care market significantly reduces the number of operating child care centers, especially in lower-income markets. Furthermore, this loss of capacity in the center-based sector due to regulation is not offset by child care centers hiring more workers or by expanding the number of home day care providers. Rather, our evidence suggests that regulating child care centers leads to more children going into the same number of family day care homes, where these arrangements are thought to be less developmentally enriching. But, on the positive side, the imposition and increased stringency of

\footnotetext{
${ }^{34}$ For example, the government subjects automobile manufacturers to fuel-economy standards, and older cars to smog checks to ensure that they meet certain emission standards. Health care professionals, and apropos of this study, child care providers, must pass detailed licensing requirements in order to practice their occupations. Several rationales are often used to justify such governmental regulations, including informational asymmetries between sellers and consumers (George Akerlof, 1970) or negative externalities that the consumption of low-quality products or services may impose on society. The latter two situations can lead to market failure, i.e., insufficient quantities of higher quality products or services are produced and consumed relative to what is socially optimal.

${ }^{35}$ For example, another regulatory response could be to require sellers to disclose the quality of their products or services (Ginger Jin and Philip Leslie, 2003).
} 
such standards, especially on the labor intensiveness of child care centers, do increase the quality services available in the centers that remain. Unfortunately, this increased quality is not shared equally by all children and parents, since the gains appear to accrue primarily to those living in higher income areas. Taken together, our results suggest that a simple characterization of whether the well-being of children (and their parents) is improved or reduced by regulations is not possible and would be misleading. Rather, there are positive and negative consequences of regulating the child care market, with some children and parents being better off and some being worse off. 


\section{References}

Akerlof, George. 1970. “The Market for Lemons: Quality Uncertainty and the Market Mechanism.” Quarterly Journal of Economics, 84(3): 488-500.

Bernal, Raquel and Michael Keane. 2010. "Quasi-structural Estimation of a Model of Childcare Choices and Child Cognitive Ability Production.” Journal of Econometrics, 156: 164189.

Besley, Timothy and Anne Case. 2000. "Unnatural Experiments? Estimating the Incidence of Endogenous Policies.” Economic Journal, 110(467): F672-F694.

Blau, David. 2000. “The Production of Quality in Child Care Centers: Another Look.” Applied Developmental Science, 4(3): 136-148.

Blau, David. 2003. "Do Child Care Regulations Affect the Child Care and Labor Markets?” Journal of Policy Analysis and Management, 22(3): 443-465.

Blau, David. 2007. “Unintended Consequences of Child Care Regulations.” Labour Economics, 14(3): 513-38.

Blau, David and Janet Currie. 2006. “Preschool, Day Care and After-School Care: Who's Minding the Kids.” In Handbook of the Economics of Education, Vol. 2, ed. Eric A. Hanushek and Finis Welch, 1163-1278. New York: Elsevier.

Blundell, Richard and Monica Casta Dias. 2009. “Alternative Approaches to Evaluation in Empirical Microeconomics.” Journal of Human Resources, 44(3): 565-640.

Chipty, Tasheem and Anne Witte. 1997. “An Empirical Investigation of Firms' Responses to Minimum Quality Standards Regulation.” National Bureau of Economic Research Working Paper No. 6104.

Chipty, Tasneem. 1995. "Economic Effects of Quality Regulations in the Daycare Industry." American Economic Review, 85(2): 419-424.

Cost, Quality and Outcomes Team. 1995. "Cost, Quality, and Child Outcomes in Child Care Centers, Executive Summary.” Economics Department, University of Colorado at Denver.

Crampes, Claude and Abraham Hollander. 1995. “Duopoly and Quality Standards.” European Economic Review, 39(1): 91-82.

Currie, Janet and V. Joseph Hotz. 2004. “Accidents Will Happen? Unintentional Childhood Injuries and the Effects of Child Care Regulations.” Journal of Health Economics, 23(1): 25-59.

Duncan, Greg J. and Christina Gibson-Davis. 2006. “Connecting Child Care Quality to Child 
Outcomes: Drawing Policy Lessons from Nonexperimental Data.” Evaluation Review, 30(5): 611-630.

Dunne, Timothy, Mark J. Roberts, and Larry Samuelson. 1988. "Patterns of Firm Entry and Exit in U.S. Manufacturing Industries.” The RAND Journal of Economics, 19(4): 495-515.

Garella, Paolo and Emmanuel Petrakis. 2008. "Minimum Quality Standards and Consumers' Information.” Economic Theory, 36(20: 283-302.

Gormley, William. 1991. "State Regulations and the Availability of Child Care Services." Journal of Policy Analysis and Management, 10(1): 78-95.

Hayes, Cheryl, John Palmer and Martha Zaslow. 1990. Who Cares for America's Children? Child Care Policy for the 1990s. Washington, DC: National Academy Press.

Heckman, James J. and Edward Vytlacil. 2005. "Structural Equations, Treatment Effects, and Econometric Policy Evaluation.” Econometrica, 73(3), 669-738.

Hofferth, Sandra L., April Brayfield, Sharon Deich, and Pamela Holcomb. 1991. National Child care Survey, 1990. Urban Institute Press, Washington, D.C.

Jin, Ginger and Philip Leslie. 2003. "The Effects of Information on Product Quality: Evidence from Restaurant Hygiene Grade Cards.” Quarterly Journal of Economics, 118(2), 40951.

Klein, Benjamin and Keith Leffer. 1981. "The Role of Market Forces in Assuring Contractual Performance.” Journal of Political Economy, 89(4): 615-641.

Lazear, Edward. 2001. "Educational Production.” Quarterly Journal of Economics, 116(2): 777803.

Leland, Hayne. 1979. "Quacks, Lemons, and Licensing: A Theory of Minimum Standards.” Journal of Political Economy, 87(6): 1328-1346.

Loeb, Susanna, Margaret Bridges, Daphna Bassok, Bruce Fuller and Russell Rumberger. 2007. "How Much is Too Much? The Influence of Preschool Centers on Children's Social and Cognitive Development.” Economics of Education Review, 26(1): 52-66.

Lowenberg, Anton D. and Thomas D. Tinnin. 1992. "Professional versus Consumer Interests in Regulation: the Case of the U.S. Child Care Industry.” Applied Economics, 24(6): 571580 .

Mocan, Naci. 2007. "Can Consumers Detect Lemons? An Empirical Analysis of Information Asymmetry in the Market for Child Care.” Journal of Population Economics, 20(4): 50731.

Mocan, Naci, Margaret Burchinal, John Morris, and Suzanne Helburn. 1995. "Models of Quality in Center Child Care." In Cost, Quality and Child Outcomes, ed. S. Helburn, Center for 
Research on Economic and Social Policy, University of Colorado at Denver.

Moulton, Brent R. 1986. "Random Group Effects and the Precision of Regression Estimates." Journal of Econometrics, 32(3): 385-397.

NICHD Early Child Care Research Network, and Greg J. Duncan. 2003. "Modeling the Impacts of Child Care Quality on Children's Preschool Cognitive Development.” Child Development, 74(5): 1454-1475.

O’Neill, Grace E. and Martin O’Connell. 2001. "State Estimates of Child Care Establishments: 1977-1997.” Working Paper Series No. 55, Population Division, U. S. Bureau of the Census.

Ronnen, Uri. 1991. "Minimum Quality Standards, Fixed Costs, and Competition.” Rand Journal of Economics, 22(4): 490-504.

Ruopp, Richard, Jeffrey Travers, Frederic Glantz and Craig Coelen. 1979. Children at the Center: Summary Findings and their Implications. Cambridge, MA: Abt Books.

Shapiro, Carl. 1986. "Investment, Moral Hazard, and Occupational Licensing." Review of Economic Studies, 53(5): 843-862.

Whitebook, Marcy, Carollee Howes, and Deborah Philips. 1989. Who Cares? Child Care Teachers and the Quality of Care in America: National Child Care Staffing Study. Oakland, CA: Child Care Employee Project.

Smith, Kristin. 2002. “Who’s Minding the Kids? Child-Care Arrangement: Spring 1997.” Current Population Reports, P70-86, Washington, DC: U.S. Census Bureau.

Xiao, Mo. Forthcoming. "Is Quality Certification Effective? Evidence from the Childcare Market.” International Journal of Industrial Organization. 
Table 1: Characteristics of Child Care Center Establishments

\begin{tabular}{|c|c|c|c|c|c|}
\hline Variable & Definition & $\begin{array}{l}1987 \\
\text { Mean }\end{array}$ & $\begin{array}{l}1992 \\
\text { Mean }\end{array}$ & $\begin{array}{l}1997 \\
\text { Mean }\end{array}$ & $\begin{array}{c}\text { Percentage } \\
\text { Change, } \\
\text { 1987-97 } \\
\end{array}$ \\
\hline Corporation & $\begin{array}{l}\text { Whether the establishment is owned by a } \\
\text { corporation: = } 1 \text { if yes; = } 0 \text { otherwise. }\end{array}$ & $\begin{array}{c}0.492 \\
(0.500)\end{array}$ & $\begin{array}{c}0.514 \\
(0.500)\end{array}$ & $\begin{array}{c}0.536 \\
(0.499)\end{array}$ & $8.9 \%$ \\
\hline Individual & $\begin{array}{l}\text { Whether the establishment is owned as a sole } \\
\text { proprietorship: = } 1 \text { if yes; = } 0 \text { otherwise. }\end{array}$ & $\begin{array}{c}0.307 \\
(0.461)\end{array}$ & $\begin{array}{c}0.317 \\
(0.465)\end{array}$ & $\begin{array}{c}0.310 \\
(0.463)\end{array}$ & $1.0 \%$ \\
\hline Partnership & $\begin{array}{l}\text { Whether the establishment is owned by a } \\
\text { partnership: = } 1 \text { if yes; = } 0 \text { otherwise. }\end{array}$ & $\begin{array}{c}0.040 \\
(0.197)\end{array}$ & $\begin{array}{c}0.028 \\
(0.165)\end{array}$ & $\begin{array}{c}0.034 \\
(0.181)\end{array}$ & $-15.0 \%$ \\
\hline Tax Exempt & $\begin{array}{l}\text { Whether all or part of the income of the } \\
\text { establishment is exempt from federal income } \\
\text { taxes: = } 1 \text { if yes; = } 0 \text { otherwise }\end{array}$ & $\begin{array}{c}0.340 \\
(0.474)\end{array}$ & $\begin{array}{c}0.311 \\
(0.463)\end{array}$ & $\begin{array}{c}0.292 \\
(0.455)\end{array}$ & $-16.4 \%$ \\
\hline Chain & $\begin{array}{l}\text { Whether the establishment belongs to a chain: = } 1 \\
\text { if yes; = } 0 \text { otherwise. }\end{array}$ & $\begin{array}{c}0.185 \\
(0.389)\end{array}$ & $\begin{array}{c}0.209 \\
(0.406)\end{array}$ & $\begin{array}{c}0.215 \\
(0.411)\end{array}$ & $14.1 \%$ \\
\hline Part Year & $\begin{array}{l}\text { Whether the establishment operates less than } 6 \\
\text { months in a year: = } 1 \text { if yes; = } 0 \text { otherwise. }\end{array}$ & $\begin{array}{c}0.040 \\
(0.197)\end{array}$ & $\begin{array}{c}0.044 \\
(0.206)\end{array}$ & $\begin{array}{c}0.029 \\
(0.454)\end{array}$ & $-27.5 \%$ \\
\hline $\begin{array}{l}\text { \# of } \\
\text { Employees }\end{array}$ & Number of employees & $\begin{array}{c}8.739 \\
(11.942)\end{array}$ & $\begin{array}{c}9.122 \\
(13.362)\end{array}$ & $\begin{array}{c}10.143 \\
(15.353)\end{array}$ & $16.1 \%$ \\
\hline Revenue & Total annual revenue (in 1000s of 1997 \$) & $\begin{array}{l}\$ 180.040 \\
(323.764)\end{array}$ & $\begin{array}{l}\$ 199.851 \\
(448.398)\end{array}$ & $\begin{array}{l}\$ 228.799 \\
(463.063)\end{array}$ & $27.1 \%$ \\
\hline Payroll & Total annual payroll (in 1000s of 1997 \$) & $\begin{array}{c}\$ 88.547 \\
(153.647)\end{array}$ & $\begin{array}{c}\$ 96.535 \\
(195.269)\end{array}$ & $\begin{array}{l}\$ 112.417 \\
(205.117)\end{array}$ & $27.0 \%$ \\
\hline $\begin{array}{l}\text { Payroll per } \\
\text { Employee }\end{array}$ & Payroll / \# Employees & $\begin{array}{r}8.935 \\
(4.480) \\
{[37,743]}\end{array}$ & $\begin{array}{r}9.538 \\
(6.222) \\
{[47,150]}\end{array}$ & $\begin{array}{c}10.011 \\
(6.189) \\
{[56,478]}\end{array}$ & $12.0 \%$ \\
\hline $\begin{array}{l}\text { Revenue per } \\
\text { Employee }\end{array}$ & Revenue / \# Employees & $\begin{array}{l}\$ 19.531 \\
(11.632) \\
{[37,743]}\end{array}$ & $\begin{array}{l}\$ 22.819 \\
(21.499) \\
{[47,150]}\end{array}$ & $\begin{array}{l}\$ 23.315 \\
(18.332) \\
{[56,478]}\end{array}$ & $19.3 \%$ \\
\hline$N$ & Number of Establishments & 40,628 & 51,299 & 61,882 & $52.3 \%$ \\
\hline
\end{tabular}


Table 2: Market-Level Characteristics of Center-based Child Care (Markets Defined as Zip Codes)

\begin{tabular}{|c|c|c|c|c|}
\hline Variable & Definition & $\begin{array}{l}1987 \\
\text { Mean }\end{array}$ & $\begin{array}{l}1992 \\
\text { Mean }\end{array}$ & $\begin{array}{l}1997 \\
\text { Mean }\end{array}$ \\
\hline No. of Establishments & Number of child care establishments in a zip code & $\begin{array}{c}3.440 \\
(3.320)\end{array}$ & $\begin{array}{c}3.734 \\
(3.522)\end{array}$ & $\begin{array}{c}4.023 \\
(3.864)\end{array}$ \\
\hline Establishment Density & No. of Establishments / No. of Children under 5 & $\begin{array}{c}0.007 \\
(0.049)\end{array}$ & $\begin{array}{c}0.008 \\
(0.075)\end{array}$ & $\begin{array}{c}0.009 \\
(0.047)\end{array}$ \\
\hline No. of Child Care Employees & Number of child care employees in a zip code & $\begin{array}{c}30.152 \\
(40.914)\end{array}$ & $\begin{array}{c}34.207 \\
(46.062)\end{array}$ & $\begin{array}{c}40.705 \\
(55.873)\end{array}$ \\
\hline No. of Entrants & Number of establishments which do not exist at $t-5$ & n.a. & $\begin{array}{c}1.942 \\
(2.108)\end{array}$ & $\begin{array}{c}1.942 \\
(2.144)\end{array}$ \\
\hline Entry Rate ${ }^{1}$ & No. of Entrants at $t$ / No. of Establishments at $t-5$ & n.a. & $\begin{array}{c}0.691 \\
(0.802)\end{array}$ & $\begin{array}{c}0.661 \\
(0.744)\end{array}$ \\
\hline No. of Exits & Number of establishments which do not exist at $t+5$ & $\begin{array}{c}1.330 \\
(1.617)\end{array}$ & $\begin{array}{c}1.423 \\
(1.695)\end{array}$ & n.a. \\
\hline Exit Rate $^{1}$ & No. of Entrants at $t /$ No. of Establishments at $t$ & $\begin{array}{c}0.383 \\
(0.364)\end{array}$ & $\begin{array}{c}0.378 \\
(0.356)\end{array}$ & n.a. \\
\hline$N$ & Number of Zip Codes & 11,404 & 13,304 & 14,966 \\
\hline
\end{tabular}

${ }^{1}$ We follow Timothy Dunne, Mark Roberts, and Larry Samuelson (1988) to construct aggregate measures of entry and exit rates. 
Table 3: Demographic Characteristics of Child Care Markets

\begin{tabular}{|c|c|c|c|}
\hline Variables & Definition & $\begin{array}{c}1990 \\
\text { Mean }\end{array}$ & $\begin{array}{c}2000 \\
\text { Mean }\end{array}$ \\
\hline Population under 5 & Population under age 5 (in thousands) & $\begin{array}{c}1.191 \\
(1.199)\end{array}$ & $\begin{array}{c}1.136 \\
(1.197)\end{array}$ \\
\hline \% Black & $\%$ Population that are African American & $\begin{array}{c}0.096 \\
(0.176)\end{array}$ & $\begin{array}{c}0.101 \\
(0.180)\end{array}$ \\
\hline \% Hispanic & \% Population that are Hispanics & $\begin{array}{c}0.059 \\
(0.126)\end{array}$ & $\begin{array}{c}0.082 \\
(0.147)\end{array}$ \\
\hline Household Size & Average household size & $\begin{array}{c}2.731 \\
(0.406)\end{array}$ & $\begin{array}{c}2.585 \\
(0.345)\end{array}$ \\
\hline Median Income & Household median income (in 1000s of 1997\$) & $\begin{array}{c}31.060 \\
(12.656)\end{array}$ & $\begin{array}{c}43.674 \\
(17.259)\end{array}$ \\
\hline$\%$ College & \% Population over age 25 with some college education & $\begin{array}{c}0.307 \\
(0.109)\end{array}$ & $\begin{array}{c}0.352 \\
(0.104)\end{array}$ \\
\hline \% Female Head with Child & \% Female-headed households with children. & $\begin{array}{c}0.058 \\
(0.037)\end{array}$ & $\begin{array}{c}0.066 \\
(0.036)\end{array}$ \\
\hline \% Female Not Working & \% Female over age 16 not working & $\begin{array}{c}0.379 \\
(0.092)\end{array}$ & $\begin{array}{c}0.370 \\
(0.085)\end{array}$ \\
\hline \% Unemployed & \% Labor force that are unemployed & $\begin{array}{c}0.062 \\
(0.037)\end{array}$ & $\begin{array}{c}0.057 \\
(0.042)\end{array}$ \\
\hline \% Work at Home & \% Working population over age 16 working at home & $\begin{array}{c}0.036 \\
(0.035)\end{array}$ & $\begin{array}{c}0.037 \\
(0.027)\end{array}$ \\
\hline \% Long Commute & $\begin{array}{l}\text { \% Working population over age } 16 \text { spending more than } 40 \\
\text { minutes commuting }\end{array}$ & $\begin{array}{c}0.282 \\
(0.138)\end{array}$ & $\begin{array}{c}0.322 \\
(0.141)\end{array}$ \\
\hline \% Rural & \% Population living in rural areas & $\begin{array}{c}0.405 \\
(0.414)\end{array}$ & $\begin{array}{c}0.381 \\
(0.403)\end{array}$ \\
\hline$N$ & Number of Zip Codes & 13,304 & 14,966 \\
\hline
\end{tabular}


Table 4: Accreditation of Child Care Center Establishments

\begin{tabular}{|c|c|c|c|c|}
\hline Variable & Definition & $\begin{array}{c}1987 \\
\text { Mean }\end{array}$ & $\begin{array}{l}1992 \\
\text { Mean }\end{array}$ & $\begin{array}{l}1997 \\
\text { Mean }\end{array}$ \\
\hline \multicolumn{5}{|l|}{ Establishments: } \\
\hline Accredit $^{1}$ & $\begin{array}{l}\text { Whether the establishment is NAEYC accredited: } \\
=1 \text { if yes; = } 0 \text { otherwise }\end{array}$ & $\begin{array}{c}0.003 \\
(0.057)\end{array}$ & $\begin{array}{c}0.017 \\
(0.128)\end{array}$ & $\begin{array}{c}0.038 \\
(0.191)\end{array}$ \\
\hline$N$ & Number of Establishments & 40,628 & 51,299 & 61,882 \\
\hline \multicolumn{5}{|l|}{ Zip Code Markets: } \\
\hline No. of Accredited & $\begin{array}{l}\text { Number of establishments which are NAEYC } \\
\text { accredited in the market }\end{array}$ & $\begin{array}{c}0.028 \\
(0.186)\end{array}$ & $\begin{array}{c}0.151 \\
(0.506)\end{array}$ & $\begin{array}{r}0.375 \\
(0.911)\end{array}$ \\
\hline Accreditation Rate & No. of Accredited / No. of Establishments & $\begin{array}{c}0.008 \\
(0.071)\end{array}$ & $\begin{array}{c}0.038 \\
(0.162)\end{array}$ & $\begin{array}{c}0.094 \\
(0.275)\end{array}$ \\
\hline 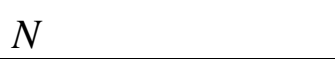 & Number of Zip Codes & 11,404 & 13,304 & 14,966 \\
\hline
\end{tabular}

${ }^{1}$ The low accreditation averages reported in this table reflect imperfect matching. We set unmatched establishments' accreditation status to zero. 
Table 5: Characteristics of Family Day Care Home (Nonemployer) Establishments at the State Level

\begin{tabular}{|c|c|c|c|}
\hline Definition & $\begin{array}{c}1987 \\
\text { Mean }\end{array}$ & $\begin{array}{c}1992 \\
\text { Mean }\end{array}$ & $\begin{array}{c}1997 \\
\text { Mean }\end{array}$ \\
\hline Number of Family Home Establishments (1000s) per State & $\begin{array}{c}4.351 \\
(4.281)\end{array}$ & $\begin{array}{c}9.589 \\
(8.956)\end{array}$ & $\begin{array}{c}9.583 \\
(9.354)\end{array}$ \\
\hline Number of Family Home Establishments per 1,000 Children under Age 5 & $\begin{array}{c}16.595 \\
(12.011)\end{array}$ & $\begin{array}{c}34.927 \\
(19.811)\end{array}$ & $\begin{array}{c}33.259 \\
(18.759)\end{array}$ \\
\hline Annual Revenue (in 1000s of 1997\$) per Family Home Establishment & $\begin{array}{l}\$ 8.240 \\
(1.567)\end{array}$ & $\begin{array}{c}\$ 7.753 \\
(1.689)\end{array}$ & $\begin{array}{c}\$ 9.382 \\
(1.921)\end{array}$ \\
\hline$N$ (States plus District of Columbia) & 51 & 51 & 51 \\
\hline
\end{tabular}


Table 6: Summary Statistics for State Child Care Center Regulations by Year

\begin{tabular}{|c|c|c|c|c|c|c|c|c|}
\hline & Mean & $\begin{array}{l}\frac{987}{\text { Number of }} \\
\text { States with } \\
\quad \text { No } \\
\text { Regulation }\end{array}$ & Mean & $\begin{array}{l}\frac{1992}{\text { Number of }} \\
\text { States with } \\
\text { No } \\
\text { Regulation }\end{array}$ & Mean & $\begin{array}{l}\frac{997}{\text { Number of }} \\
\text { States with } \\
\quad \text { No } \\
\text { Regulation }\end{array}$ & Mean & $\begin{array}{l}\text { Years } \\
\text { Number of } \\
\text { States that } \\
\text { changed } \\
\text { Regulation }\end{array}$ \\
\hline \multicolumn{9}{|c|}{ Regulations on Labor Intensiveness: Minimum Staff-child Ratio by Age of Children } \\
\hline 0 - 11 months & 0.225 & 5 & 0.226 & 0 & 0.229 & 0 & 0.226 & 9 \\
\hline 11 - 23 months & 0.192 & 5 & 0.190 & 0 & 0.192 & 0 & 0.192 & 10 \\
\hline 24 - 35 months & 0.138 & 4 & 0.137 & 0 & 0.138 & 0 & 0.137 & 11 \\
\hline 36 - 47 months & 0.096 & 4 & 0.095 & 0 & 0.095 & 0 & 0.095 & 8 \\
\hline 48 - 59 months & 0.082 & 4 & 0.081 & 0 & 0.082 & 0 & 0.082 & 6 \\
\hline 60+months & 0.072 & 4 & 0.068 & 0 & 0.068 & 0 & 0.069 & 9 \\
\hline Average & 0.133 & 4 & 0.133 & 0 & 0.134 & 0 & 0.133 & 18 \\
\hline \multicolumn{9}{|c|}{ Regulations on Staff Qualifications: Min. Educational Requirement (in years of schooling) by Type of Staff } \\
\hline For Directors & 13.625 & 15 & 13.644 & 6 & 13.739 & 5 & 13.673 & 15 \\
\hline For Teachers & 12.464 & 23 & 12.600 & 16 & 12.595 & 14 & 12.560 & 12 \\
\hline Average & 11.660 & 15 & 11.467 & 5 & 11.681 & 4 & 11.599 & 19 \\
\hline
\end{tabular}


Table 7: Estimated Marginal and Average Effects of State Regulations on the Number of Child Care Center Establishments per Market $^{1}$
(1)
(2)

(3)

(4)

(5)

\section{Panel A: The Effects of Single Measures of Child Care Center Regulations}

Min. Staff-Child Ratio, Infants

No Standard Imposed ${ }^{3}$

Min. Staff-Child Ratio, Infants $\times$ Median Income

\section{$-3.519 * * *$}

$-3.297 * * *$

$-1.024^{* *}$

$-0.690 *$

$-1.898$

$-0.629 *$

$-5.617 * * *$

$-1.202 * *$

$-11.693 * * *$

No Standard Imposed $\times$ Median Income

Ave. Effect of Regulation, Min. Staff-Child Ratio ${ }^{1}$

Min. Educ. Requirement, Directors

No Standard Imposed ${ }^{3}$

Min. Educ. Require., Directors $\times$ Median Income

No Standard Imposed $\times$ Median Income

Ave. Effect of Regulation, Min. Educ. Requirement ${ }^{1}$

$\mathrm{R}^{2}$

Panel B: The Effects of Averaged Measures of Child Care Center Regulations

Ave. Min. Staff-Child Ratio

No Standards Imposed ${ }^{3}$

Ave. Min. Staff-Child Ratio $\times$ Median Income

No Standards Imposed $\times$ Median Income

Ave. Effect of Regulation, Min. Staff-Child Ratio ${ }^{1}$

Ave. Min. Educ. Requirement

No Standards Imposed ${ }^{3}$

Ave. Min. Educ. Requirement $\times$ Median Income

No Standards Imposed $\times$ Median Income

Ave. Effect of Regulation, Min. Educ. Requirement ${ }^{1}$ $\mathrm{R}^{2}$

Year Fixed Effects

State Fixed Effects

Number of Observations

Unit of Observations

${ }^{1}$ The Ave Effect of Regulation is the effect of imposing a restap

lation is the effect of imposing a regulation, at the mean value of the standard (see corresponding values in the "Mean" column for "All Years") relative to no standard at all. See Section III for a description of how these effects were calculated. Estimates in italics are statistically significant, based on significance of coefficients on regulation $\times$ median household income interactions.

${ }^{2}$ The dummy variable is equal to 1 if a state imposed no standard for any of the regulations used to form the average measure and equal to 0 otherwise.

* significant at $10 \%$; ** significant at $5 \%$; *** significant at $1 \%$. 
Table 8: Differences in Estimated Marginal and Average Effects of State Regulations by Median Income of Local Market

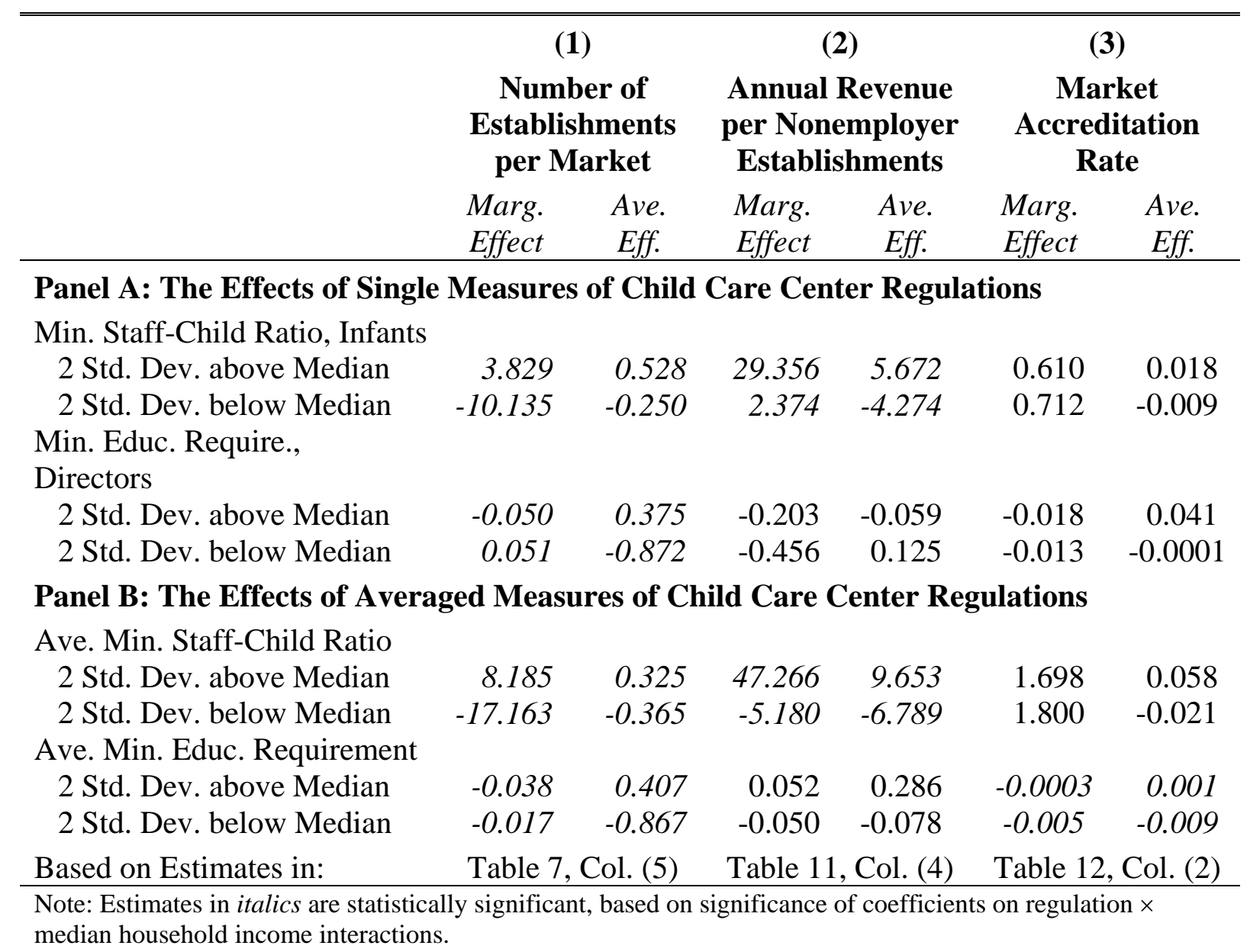


Table 9: Estimated Effects of State Regulations on the Number of Child Care Center Establishments per Market: Robustness Checks

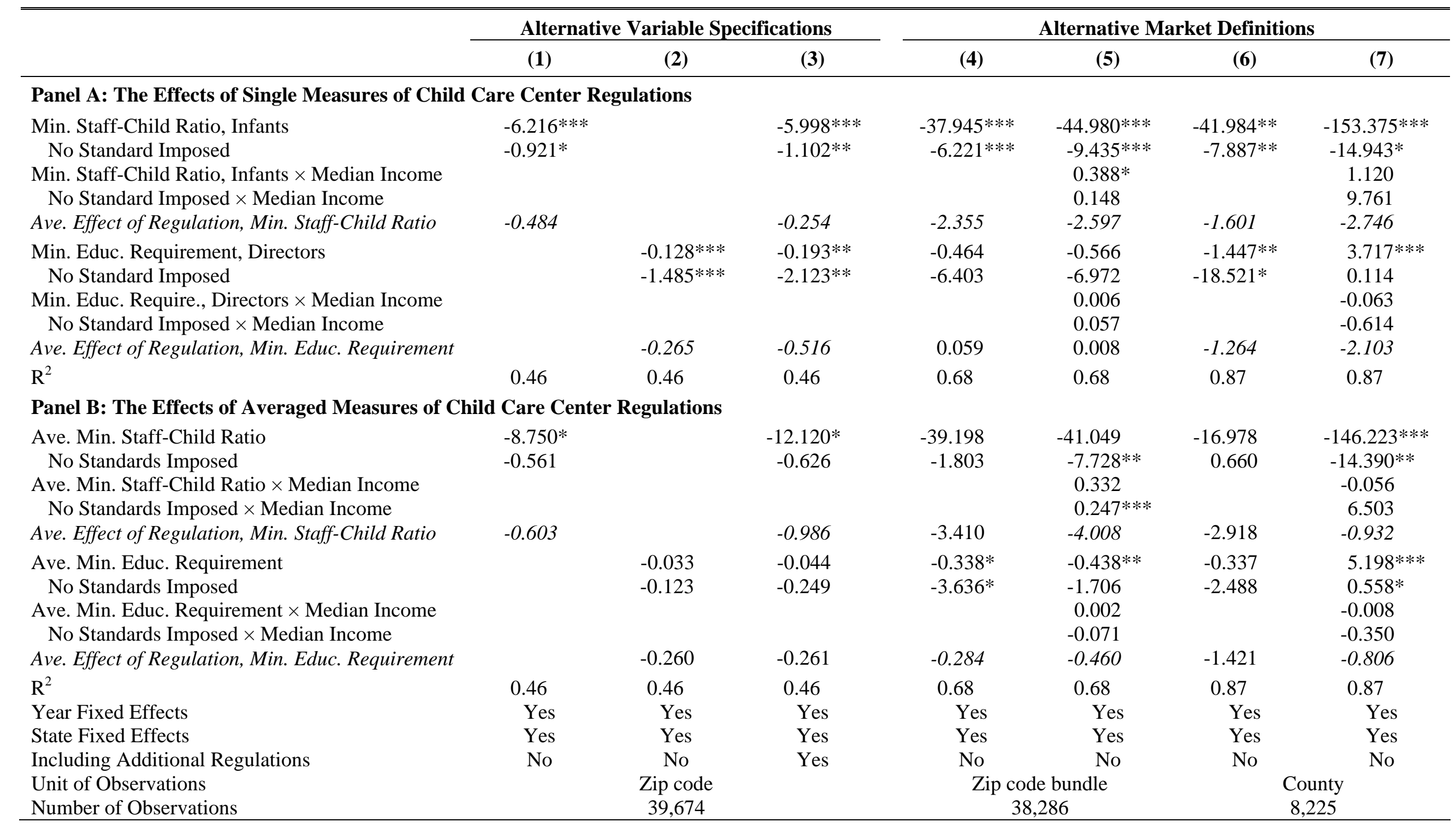


Table 10: Estimated Effects of State Regulations on Number of Employees per Child Care Center

(1) (2) (3)

Panel A: The Effects of Single Measures of Child Care Center Regulations

Min. Staff-Child Ratio, Infants

No Standard Imposed

$-2.725 \quad 10.992 * * *$

$1.842 \quad 5.552$

Min. Staff-Child Ratio, Infants $\times$ Median Income

No Standard Imposed $\times$ Median Income

1.074

4.106**

0.069

$-0.680$

Ave. Effect of Regulation, Min. Staff-Child Ratio

Min. Educ. Requirement, Directors

No Standard Imposed

$\begin{array}{lccc} & -0.103^{* *} & & 0.038 \\ -1.690 & -1.183 & 0.347 & 0.329 \\ 0.219^{* *} & 0.280^{*} & 0.172 & -0.064 \\ 2.308^{*} & 4.032^{*} & 2.737 & 0.117 \\ & -0.003 & & 0.006 \\ & -0.073^{*} & & 0.064 \\ 0.686 & 0.819 & -0.385 & -0.415 \\ 0.10 & 0.10 & 0.05 & 0.05\end{array}$

Min. Educ. Require., Directors $\times$ Median Income

No Standard Imposed $\times$ Median Income

Ave. Effect of Regulation, Min. Educ. Requirement $\mathrm{R}^{2}$

0.10

0.10

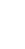

B: The Effects of Averaged Measures of Child Care Center Regulati

Ave. Min. Staff-Child Ratio

No Standards Imposed

Ave. Min. Staff-Child Ratio $\times$ Median Income

No Standards Imposed $\times$ Median Income

Ave. Effect of Regulation, Min. Staff-Child Ratio

Ave. Min. Educ. Requirement

No Standards Imposed

Ave. Min. Educ. Requirement $\times$ Median Income

No Standards Imposed $\times$ Median Income

Ave. Effect of Regulation, Min. Educ. Requirement

$\mathrm{R}^{2}$

Year Fixed Effects

State Fixed Effects

Establishment Fixed Effects

Unit of Observations

Number of Observations

\begin{tabular}{cccc}
-5.791 & $19.386^{* *}$ & -9.161 & -5.068 \\
0.290 & $3.891^{*}$ & -1.506 & -0.882 \\
& $-0.736^{* * *}$ & & -0.136 \\
& $-0.126^{* *}$ & & -0.020 \\
-1.060 & -0.414 & 0.288 & 0.269 \\
0.022 & 0.037 & -0.026 & -0.075 \\
-0.156 & 1.073 & 0.004 & -0.615 \\
& -0.001 & & 0.001 \\
& $-0.046^{*}$ & & 0.018 \\
0.411 & 0.456 & -0.306 & -0.460 \\
0.10 & 0.10 & 0.05 & 0.05 \\
Yes & Yes & Yes & Yes \\
Yes & Yes & Yes & Yes \\
No & No & Yes & Yes \\
\multicolumn{5}{c}{ Establishment } \\
149,102 & 149,102 & 93,063 & 93,063
\end{tabular}


Table 11: Estimated Effects of State Regulations on the Family Home Day Care (Nonemployer) Sector

\begin{tabular}{|c|c|c|c|c|}
\hline \multirow[t]{2}{*}{ Dependent Variables } & \multicolumn{2}{|c|}{$\begin{array}{l}\text { Number of Nonemployer } \\
\text { Establishments } \\
\text { per } 1,000 \text { Children } \\
\text { under Age } 5\end{array}$} & \multicolumn{2}{|c|}{$\begin{array}{l}\text { Annual Revenue } \\
\text { (in millions of 1997\$) } \\
\text { per Nonemployer } \\
\text { Establishment }\end{array}$} \\
\hline & (1) & (2) & (3) & (4) \\
\hline \multicolumn{5}{|c|}{ Panel A: The Effects of Single Measures of Child Care Center Regulations } \\
\hline Min. Staff-Child Ratio, Infants & 40.76 & -36.717 & $27.028 * * *$ & -0.690 \\
\hline No Standard Imposed & 13.293 & -10.940 & $5.894 * * *$ & $5.247 * *$ \\
\hline Min. Staff-Child Ratio, Infants $\times$ Median Income & & $2.891 *$ & & $0.533^{* *}$ \\
\hline No Standard Imposed × Median Income & & 0.887 & & -0.076 \\
\hline Ave. Effect of Regulation, Min. Staff-Child Ratio & -4.081 & -4.615 & 0.214 & 0.699 \\
\hline Min. Educ. Requirement, Directors & $-1.976 *$ & -4.144 & $-0.445 * * *$ & -0.485 \\
\hline No Standard Imposed & -27.476 & -53.699 & $-6.006 * * *$ & -6.777 \\
\hline Min. Educ. Require., Directors $\times$ Median Income & & 0.072 & & 0.005 \\
\hline No Standard Imposed × Median Income & & 0.894 & & 0.072 \\
\hline Ave. Effect of Regulation, Min. Educ. Requirement & 0.458 & -0.152 & 0.078 & 0.033 \\
\hline $\mathrm{R}^{2}$ & 0.96 & 0.96 & 0.93 & 0.94 \\
\hline \multicolumn{5}{|c|}{ Panel B: The Effects of Averaged Measures of Child Care Center Regulations } \\
\hline Ave. Min. Staff-Child Ratio & 38.847 & -156.298 & $23.838 * * *$ & -11.135 \\
\hline No Standards Imposed & 5.842 & 14.897 & $3.637 * *$ & $7.175^{* * *}$ \\
\hline Ave. Min. Staff-Child Ratio $\times$ Median Income & & $6.242 * *$ & & $1.036 * *$ \\
\hline No Standards Imposed × Median Income & & -0.519 & & $-0.187 * * *$ \\
\hline Ave. Effect of Regulation, Min. Staff-Child Ratio & -0.675 & 6.221 & 0.467 & 1.432 \\
\hline Ave. Min. Educ. Requirement & -0.224 & -0.903 & 0.056 & -0.061 \\
\hline No Standards Imposed & 0.327 & -14.060 & 0.595 & -0.588 \\
\hline Ave. Min. Educ. Requirement $\times$ Median Income & & 0.017 & & 0.002 \\
\hline No Standards Imposed × Median Income & & 0.423 & & 0.016 \\
\hline Ave. Effect of Regulation, Min. Educ. Requirement & -2.925 & -3.428 & 0.055 & 0.104 \\
\hline $\mathrm{R}^{2}$ & 0.96 & 0.96 & 0.92 & 0.94 \\
\hline Year Fixed Effects & Yes & Yes & Yes & Yes \\
\hline State Fixed Effects & Yes & Yes & Yes & Yes \\
\hline Unit of Observations & \multicolumn{2}{|c|}{ State } & \multicolumn{2}{|c|}{ State } \\
\hline Number of Observations & \multicolumn{2}{|c|}{153} & \multicolumn{2}{|c|}{153} \\
\hline
\end{tabular}


Table 12: Estimated Effects of State Regulations on the Accreditation of Child Care Centers

\section{Dependent Variables}

Market Accreditation Rate

(1)

(2)

Panel A: The Effects of Single Measures of Child Care Center Regulations

Min. Staff-Child Ratio, Infants

No Standard Imposed

Min. Staff-Child Ratio, Infants $\times$ Median Income

No Standard Imposed $\times$ Median Income

Ave. Effect of Regulation, Min. Staff-Child Ratio

Min. Educ. Requirement, Directors

No Standard Imposed

Min. Educ. Require., Directors $\times$ Median Income

No Standard Imposed $\times$ Median Income

Ave. Effect of Regulation, Min. Educ. Requirement

$\mathrm{R}^{2}$

\begin{tabular}{ll}
$0.639 * * *$ & $0.723 * * *$ \\
$0.139 * * *$ & $0.176 * * *$ \\
& -0.002 \\
& -0.001 \\
0.005 & 0.004 \\
$-0.017 * *$ & -0.013 \\
$-0.244 * * *$ & -0.173 \\
& -0.0001 \\
0.012 & -0.002 \\
0.09 & 0.020 \\
\hline
\end{tabular}

$0.639 * * *$

$0.723 * * *$

$-0.002$

$-0.001$

Panel B: The Effects of Averaged Measures of Child Care Center Regulations

Ave. Min. Staff-Child Ratio

$1.735 * * *$

$1.811^{* * *}$

No Standards Imposed

$0.208 * * *$

$0.224 * * *$

Ave. Min. Staff-Child Ratio $\times$ Median Income

No Standards Imposed $\times$ Median Income

Ave. Effect of Regulation, Min. Staff-Child Ratio

Ave. Min. Educ. Requirement

No Standards Imposed

Ave. Min. Educ. Requirement $\times$ Median Income

No Standards Imposed $\times$ Median Income

Ave. Effect of Regulation, Min. Educ. Requirement

$\mathrm{R}^{2}$

Year Fixed Effects

State Fixed Effects

Unit of Observations

Number of Observations
$-0.002$

$-0.001$

$0.023 \quad 0.040$

$-0.003-0.006 * * *$

$-0.029-0.060 * *$

$0.0001 * * *$

$0.001^{*}$

$-0.006 \quad 0.004$

$0.09 \quad 0.09$

Yes Yes

Yes Yes

Zip Code

39,674 39,674 